\title{
Growing trees: The acquisition of the left periphery
}

\section{Glossa}

a journal of general linguistics

\author{
RESEARCH
}

\section{NAAMA FRIEDMANN}

ADRIANA BELLETTI (1)

LUIGI RIZZI (1)

*Author affiliations can be found in the back matter of this article

\begin{abstract}
We suggest here a Growing Trees approach for the description of the acquisition of various syntactic structures in Hebrew, based on the main results reported in Friedmann and Reznick (this volume) and on our own research on a corpus of natural productions. The heart of our account is that stages of acquisition follow the geometry of the syntactic tree, along the lines of the cartographic analysis of the clause, with early stages of acquisition corresponding to small portions of the adult syntactic tree, which keeps growing with the growth of the child. The lower parts of the tree are acquired first, and higher parts are acquired later. We propose three stages of acquisition connected to the development of functional layers of the syntactic tree. In the first stage, the IP is acquired, including the lexical and inflectional layers. This allows for the appearance of A-movement structures, including SV/VS alternations with unaccusative verbs, alongside SV sentences with unergative/transitive verbs. The second stage involves the acquisition of the lower part of the left periphery, up to QP, which allows for the acquisition of subject and object Wh questions, some adjunct questions, yes/no questions, and sentence-initial adverbs. In the third stage, the rich structure of the left periphery is completely acquired, including the higher CP field. This is the stage in which sentential embedding (of finite declarative and interrogative clauses), subject and object relative clauses, why questions, and topicalization appear. A further, different type of stage, which occurs on the already-grown tree and which is independent of structure building, is the acquisition of intervention configurations, allowing for the mastery of structures involving movement of a lexically-restricted object across an intervening lexicallyrestricted subject. The paper illustrates the fruitful dialogue between the science of syntax acquisition and the cartography of syntactic structures.
\end{abstract}

CORRESPONDING AUTHOR:

\section{Naama Friedmann}

Tel Aviv University, Tel Aviv, Israel

naamafr@tauex.tau.ac.il

\section{KEYWORDS:}

syntax; language acquisition; intervention; Hebrew; psycholinguistics; cartography; left periphery

\section{TO CITE THIS ARTICLE:}

Friedmann, Naama, Adriana Belletti and Luigi Rizzi. 2021. Growing trees: The acquisition of the left periphery. Glossa: a journal of general linguistics 6(1): 131. 1-38. DOI: https://doi. org/10.16995/glossa.5877 


\section{Introduction}

In the early stages of the acquisition of syntax, not all syntactic structures are initially available to the child, but they develop gradually. Here we propose an account for the order of acquisition of various syntactic structures. The heart of our account is that the stages of acquisition follow the geometry of the syntactic tree, along the lines of the cartographic analysis of the clause, with special reference to the left periphery (LP), as described by Rizzi (1997) and Rizzi \& Bocci (2017). The lower parts of the tree are acquired first, and then higher and higher parts are acquired. Thus, early stages of acquisition correspond to only a small, lower, portion of the adult syntactic tree, which keeps growing with the growth of the child.

We believe that cartographic research and the study of development can interact in fruitful ways. In one direction, cartography provides detailed maps of the fundamental zones of the syntactic tree which may bring to light patterns underlying apparently disparate developmental effects. In the other direction, developmental data may provide original evidence on the organization of complex structural maps. In this paper we illustrate this fruitful dialogue, suggesting a Growing Trees account for the order of acquisition that emerges from the findings of a study by Friedmann \& Reznick (this volume), based on a sentence repetition task and the analysis of a corpus of spontaneous production. The evidence will be completed by an independent corpus study that we conducted to test new predictions that are raised by the Growing Trees account.

Under the described growing trees view, young children may be using only lower portions, of various sizes, of clausal structures, without higher layers. Given a complete representation like (1) in the adult grammar, children may use only layer A, creating the treelet as in (2), or layers A and B (3), or all three layers A, B, and C (which then becomes the adult state, as in (1)). Importantly, we do not expect to have a structure in which an internal layer B is missing as in (4), where only A and C are acquired.

(1)

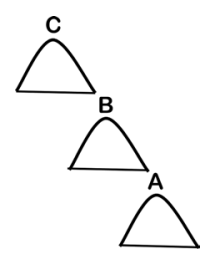

(2)

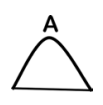

(3)

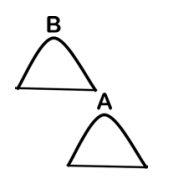

(4)
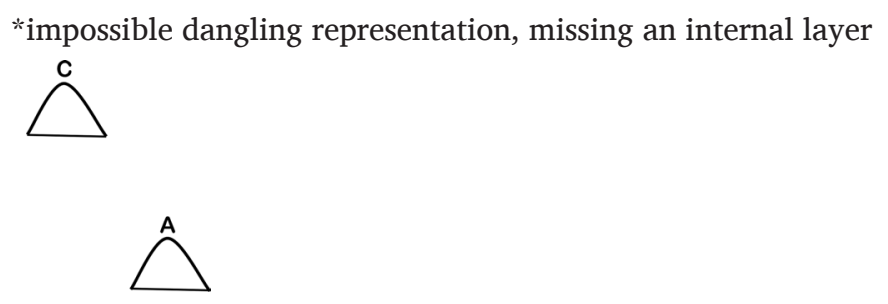

Such direction, from lower to higher layers, is consistent with standard assumptions on the bottom-up nature of syntactic computations, going from the contentive part of the clause, the lexical layer, to the functional ones, the functional spine of the clause (Chomsky 1995 and much subsequent literature). ${ }^{1}$

This logic is akin to the logic of truncation (Rizzi 1993/94), used to capture the structural properties of certain salient non-target-consistent constructions in child language such as root null subjects in

1 Here we are dealing mainly with the functional structure above the VP and not the lower part, within the lexical layer. It would be interesting, in a future development, to find out whether a similar bottom-up order of acquisition can be detected within the lexical layer as well (which may in turn instantiate an articulated structural map, see e.g., Ramchand 2008). See also Armon-Lotem (2005) for such an account for the internal structure of the DP. 
the acquisition of a non-null subject language, and root infinitives, and to tree pruning accounts for syntactic impairments in aphasia (Friedmann \& Grodzinsky 1997; 2000; Friedmann 2001; 2002a; b; 2006), as well as in the domain of child vs. adult L2 acquisition (Prévost \& White 2000a; b).

The truncation and the growing tree views have in common the idea that lower layers cannot be omitted if higher ones are present. They differ, though, in one crucial respect: under truncation the higher layers of the structure are available (though not necessarily used), whereas under growing trees the higher layers of the tree are not yet available at the particular stage of development under consideration. Under truncation, higher layers could be used, given a structural requirement of the construction, whereas under growing trees, if a layer has not been acquired yet, the child would not be able to produce the construction that involves it. The two devices are not inconsistent, but the growing tree mechanism may characterize earlier stages of acquisition (see De Lisser et al., this volume, for discussion).

The logic of growing trees is also in line with the conceptualization suggested by several researchers, according to which the early tree is smaller, and the acquisition of syntax involves the acquisition of higher parts of the tree. Some of these researchers suggested that the small, early tree includes no functional nodes, only VP (Lebeaux 1988; Platzack 1990; Radford 1990; 1996; Guilfoyle \& Noonan 1992), whereas Clahsen and colleagues (Clahsen 1990/1991; Clahsen et al. 1993/1994; 1996) suggested that the early tree includes a single functional projection above VP. The work of Armon-Lotem (2008a) also suggested the gradual bottom-up steps of acquisition of the IP as well as of other phrasal categories. We continue this basic conceptualization with the proposal that the tree indeed grows, but in a multi-staged developmental path, which crucially relies on cartographic representations. The fundamental innovation of our approach is the use of syntactic cartography as a guiding map to capture stages of maturation and depict the development of the syntactic tree. Our Growing Trees approach provides a more fine-grained description of the path of acquisition, going beyond the lexical vs. functional stages, and illustrates various stages of the growth of the functional structure. ${ }^{2}$ The detailed representations offered by the cartographic maps generate more refined structure-based predictions, compared to traditional representations. This allows us to capture new facts regarding order of acquisition that may have remained unnoticed otherwise.

Once cartographic representations are adopted, possible truncation sites and the potential stages in the growing tree are significantly multiplied, so the important empirical question that arises is which layers are actually observed in each acquisition stage. In this paper we will focus in particular on the observed growing stages in the left periphery of the clause.

Our evidence will be grounded on data from Hebrew, so we begin (Section 1.1) with presenting the cartographic map for Hebrew (mainly its left periphery), inspired by the one developed for Romance (starting from Rizzi 1997), and based in part on the first sketch provided in Shlonsky (2014). Then, in Section 2, we describe the acquisition data and show how the "growing trees" approach accounts for the observed developmental patterns. Section 3 develops the Growing Trees account. Section 4 looks at the proposed stages in detail, and, through a systematic reference to the cartographic map of the Hebrew left periphery, derives predictions regarding the order of acquisition of yes/ no questions, adverb placement, and why questions. Thus, further theoretical questions are raised by reconsidering the same spontaneous speech corpus originally used by Friedmann \& Reznick (this volume), leading to new analyses of specific constructions that are not undertaken in the Friedmann \& Reznick's contribution. These new analyses are all reported in Section 4 (Appendix A reports the methodological details on the corpus used). Section 5 summarizes the paper with the main conclusions and outcomes derived from the dialogue between theoretical research within the cartographic guidelines and acquisition data, and indicates new venues for further research.

\subsection{On the cartography of the Hebrew left periphery}

Intensive cartographic research over the last two decades led to a detailed map of the higher (so-called left) part of the clause along the lines given in (5) for Italian/Romance (schematic description adapted from Rizzi \& Bocci 2017): ${ }^{3}$

2 We do not engage here in an empirical investigation of a potential pre-functional stage, see Section 4.6 for some relevant considerations.

3 The main simplification of (5) with respect to Rizzi \& Bocci, 2017 is that (5) does not include the proliferation of topic positions which is characteristic of Italian, and only specifies the topic position higher than Q/Foc, which is robustly attested cross-linguistically. 
Assuming the inventory of functional positions in the left periphery in (5), let us now review some fundamental aspects of the rich map of the periphery of the clause in Hebrew, which will offer some guidance for the interpretation of the developmental findings.

\section{Force $>$ Top (embedded declaratives introducer above topic)}

Starting from the uppermost part of the tree, Force is the highest head in Hebrew. This can be seen in the distribution of the complementizer and embedding marker she-, marking declarative force. The examples in (6) show that she- in Force is higher than Top. (6a) demonstrates this for the declarative embedding marker, which precedes the topic, and (6b) shows the same order for the relative complementizer, preceding a resumptive pronoun ${ }^{4}$ in topic position, an available option in object relative clauses in Hebrew. The opposite order (Top $>$ she) would give rise to ill-formedness, as demonstrated by the ungrammatical (6'). So the order Force $>$ Top is established. ${ }^{5}$

a. Ani xoshev [ Force $_{\text {she- }}\left[_{\text {TopP }}\right.$ et ha- glida ha- zo [ha- yalda axla.]]]

I think that- P.ACC the-ice.cream the-this the-girl ate

'I think that this girl ate this ice-cream.'

b. Ha-glida [ha- yalda axla]] hayta yeruka. the-ice.cream.FEM that- P.ACC-3SG.FEM the-girl ate was green

'The ice-cream that the girl ate was green.'

*Ani xoshev $\left[_{\text {TopP }}\right.$ et ha- glida ha- zo [ ${ }_{\text {Forcep }}$ she- [ha- yalda axla.]]
$\begin{array}{lll}\text { I think P.ACC the-ice.cream the-this that- the-girl ate }\end{array}$

\section{Int > Top (embedded interrogative yes/no question marker above topic)}

The introducer of embedded yes/no questions (the interrogative marker $\mathrm{im}$ ) also precedes the topic in Hebrew, an order that is visible in embedded interrogatives with topicalized elements. The order in (7), in which im precedes the topic, indicates that the position that is occupied by Int in the surface is higher than the Top position. The point is confirmed by the ungrammaticality of (7'), with Int following Top.

$$
\begin{aligned}
& \text { Ani toha }\left[{ } _ { \text { Int } } \text { im } \left[_{\mathrm{TopP}}\right.\right. \text { et nisui ha- xazara ha- arox ha- ze } \\
& \text { I wonder if P.ACC experiment the-repetition the-long the-this } \\
& \text { [miri herica be-acma.]]] } \\
& \text { Miri ran by-herself } \\
& \text { 'I wonder whether Miri ran this long repetition experiment by herself.' }
\end{aligned}
$$

$$
\begin{aligned}
& \text { *Ani toha }\left[_ { \text { TopP } } \text { et nisui ha-xazara ha- arox ha-ze } \left[_{\text {IntP }}\right.\right. \text { im } \\
& \text { I wonder P.ACC experiment the-repetition the-long the-this if } \\
& \text { [miri herica be-acma.]]] } \\
& \text { Miri ran by-herself }
\end{aligned}
$$

We keep Force and Int separate as in (5) because cross-linguistic evidence shows that Int can in fact be lower than the declarative Force marker (Rizzi 2001; 2013a). Nevertheless, the distinction does not play a critical role in the Hebrew map: we follow Shlonsky's (2014) analysis

\footnotetext{
4 We illustrate the position of the topic with respect to she- in an object relative using the resumptive pronoun because other topics inside relatives would produce a mild island effect. When the resumptive pronoun is in topic position this island effect is overcome since the connection is established between the head of the relative and the resumptive pronoun in topic position (and then from the resumptive pronoun to the gap in object position), not across a distinct topic position. We rely here on Borer's (1984) analysis of this construction.

5 Given that in Hebrew there is no morphosyntactic distinction between topicalization and focalization structures (they differ in interface properties: prosody and properties of information structure; see Shlonsky 2014, for discussion), in the corpus study we make the simplifying assumption that OSV structures are typically instances of topicalization. We believe this idealization is legitimate because Hebrew, like Romance, uses the left peripheral focus position only for very special focal interpretations (such as corrective or mirative focus: see Bianchi et al. 2016, on Italian), whereas run of the mill new information focus is expressed IP-internally (Shlonsky 2014: 329; Belletti 2004). Given the rarity of the special uses, we do not believe our idealization to importantly overestimate the occurrence of topics in the corpus of young children.
} 
and assume that im in Hebrew moves from Int to Force, hence it always ends up occupying the highest peripheral position on the surface.

\section{Top $>$ Q (topic above wh questions)}

Top, in turn, is higher than $\mathrm{Q}$, the position to which the Wh element of root Wh questions moves. ${ }^{6}$ One central property that emerges, language after language, is that when a topic and a Wh phrase co-occur they do so in the order Top $>$ Wh. ${ }^{7}$ Hebrew is no exception with regard to this property (see also Shlonsky 2014), as illustrated by the minimal pair in (8), containing a contrastive topic, where the sentence is grammatical with the topicalized object preceding the wh-element (8), but ungrammatical in the reversed order (8'):

(Yoni already presented the acquisition paper...)

$\ldots$ ve- $\left[_{\text {TopP }}\right.$ et ha- maamar al afazia, $\left[_{\mathrm{QP}} \mathrm{mi}\right.$ roce lehacig?]]

... and- P.ACC the-paper about aphasia who wants to.present

... 'and who wants to present the-paper about aphasia?'

*... ve- $\left[\left[_{\mathrm{QP}}\right.\right.$ mi $\left[_{\mathrm{TopP}}\right.$ et ha- maamar al afazia roce lehacig]]?

* and- who P.ACC the-paper about aphasia wants to.present?

Int $>Q$ (why questions above other wh questions and above topic)

Lama (why) clearly differs from other Wh elements in Hebrew in that it precedes the topic:

(You presented the acquisition paper very nicely...)

.... ve- $\left[_{\text {IntP }}\right.$ lama $\left[_{\text {TopP }}\right.$ et ha- maamar al afazia [at lo roca lehacig?] $]$

.... and- why P.ACC the-paper about aphasia you no want to.present

... 'and why don't you want to present the-paper about aphasia?'

The orderings Why $>$ Top and Top $>$ Wh in (8)-(9) clearly show, by transitivity, that lama occupies a position higher than the position of other Wh elements. On the basis of different kinds of evidence, Rizzi (2001) proposed that perché (why) in Italian occupies the position of Specifier of the head Int, higher than $Q$ in (5), and also used to express if-type elements, introducing yes/no questions. If the Spec/Int hypothesis is extended to lama in Hebrew, the contrast (8)-(9) is captured, and confirms the ordering Int $>$ Q for Hebrew, already established (by transitivity) in (7). ${ }^{8}$

6 In the initial cartographic paper (Rizzi 1997), the landing site of Wh movement (called QP in Figure 1) was identified with the Focus position also occurring in the low zone of the left periphery. We do not enter here into a discussion of the connection between Wh elements and focus in main questions (on which see Bocci et al. 2018, for a possible mixed focus $+Q$ position). What is crucial for the current discussion is the fact that the landing site of the Wh element in main questions is in the low zone of the left periphery, independently from the label of the attracting head.

7 This is in turn a particular instantiation of the fact that topics are higher than focalized phrases, and Wh and focus in main clauses are often clearly associated across languages (Bocci et al. 2018, and footnote 6). Our evidence here is about Wh, because instances of (non-Wh) focus are not easily identifiable from the corpus study (See footnote 5).

8 The order why > Top illustrated by (9) is preferred, but the opposite order is not excluded:

(i) ? ....ve- $\left[_{\text {TopP }}\right.$ et ha- maamar al afazia $\left[\left[_{\text {IntP }}\right.\right.$ lama at lo roca lehacig? ] ] ....and- P.ACC the-paper about aphasia why you not want to.present

In embedded interrogatives the contrast becomes sharper, with why > Top being the only possible order:

(ii) Ani toha $\left[_{\text {IntP }}\right.$ lama $\left[_{\text {Topp }}\right.$ et nisui ha-xazara ha- arox ha- ze [Hedva herica be-acma.]]] I wonder why P.ACC experiment the-repetition the-long the-this Hedva ran in-herself 'I wonder why did Hedva run this long repetition experiment by herself.'

(iii) *Ani toha $\left[_{\text {Topp }}\right.$ et nisui ha-xazara ha- arox ha- ze [ IntP lama [Hedva herica be-acma. $\left.]\right]$ I wonder P.ACC experiment the-repetition the-long the-this why Hedva ran in-herself

So, the marginal acceptability of (i) may illustrate the option of an additional clause-initial topic position in main, but not in embedded clauses. That root environments may have more positions than embedded environments is not unfamiliar (see Ross' 1973 Penthouse Principle). We will not further investigate the ordering in (i) here. What is crucial for us is the contrast (8)-(9), which establishes that in Hebrew (as in many other languages) why occupies a higher position than other Wh elements. 
Adverbs can be preposed to the LP, and they appear to be hosted in a dedicated position, Mod(ifier), a position distinct from Top (Rizzi 2004). To examine the position of Mod within the LP, we first select adverbs that do not easily topicalize and therefore best illustrate movement to Mod. We then examine the position of such adverbs relative to other layers. Suddenly (pitom) seems to be such an adverb: Suddenly can appear in the left periphery, as indicated by its position before the subject in (10). To the extent that the subject delimits the highest part of IP, the occurrence of the adverb before the subject shows that Mod is in the left periphery.

$$
\begin{aligned}
& \text { Pitom Yoni hitxarfen ve- halax. } \\
& \text { suddenly Yoni flipped_out and-left } \\
& \text { 'Suddenly Yoni flipped out and left.' }
\end{aligned}
$$

Mod necessarily occupies a low position in the LP, in fact lower than Q - the position occupied by Wh elements for argument Wh questions as in (8) (and some adjunct, but not why, questions, see discussion above), as shown by the following contrast between (11) and (11'), demonstrating that suddenly can follow Wh but cannot precede it. ${ }^{9}$

$$
\begin{aligned}
& \text { [Q }_{\mathrm{Q}} \text { Mi }\left[_{\text {Mod }}\right. \text { pitom kam ve-halax?] } \\
& \text { who suddenly stood_up and-left } \\
& \text { 'Who suddenly stood up and left?' }
\end{aligned}
$$

$$
\begin{aligned}
\text { ?? }\left[_{\text {Mod }}\right. & \text { Pitom }\left[\begin{array}{l}
\text { mi } \\
\text { sam }
\end{array} \text { ve-halax?] }\right] \\
& \text { suddenly who stood_up and-left }
\end{aligned}
$$

\section{Force, Int, Top, Q, Mod > Fin}

In Hebrew there is no overt morphological marker for the Fin head, lexicalizing the Fin position. We take the surface position of the inflected verb in inversion structures as the manifestation of Fin. Following much current literature starting from Shlonsky (1997), we assume that the inversion between the subject and the inflected verb is licensed by the movement of another element to the left periphery. More specifically, we assume that an element that moves to the front passes through Spec of Fin, where it allows for head movement of the inflected verb, much as in V2 type phenomena. ${ }^{10}$ Adverbs (12), Wh elements (13), topics (14), and relativized phrases (15a) all pass through spec Fin, where they license movement of the finite verb to Fin, and then continue to their final destinations, where they get their scope-discourse interpretation.

We can observe in (12) that the adverb in Mod can precede the preposed finite verb, in Fin, which precedes the subject (in the higher part of IP). This order shows that Mod is higher than Fin.

$$
\begin{aligned}
& \text { Adverb in Mod }>\text { Fin } \\
& \text { [ }_{\text {ModP }} \text { Pitom [ [inP lakax [ }{ }_{\text {IP }} \text { Yoni et ha- duvdevanim ve- halax.]] } \\
& \text { suddenly took Yoni P.ACC the-cherries and-left }
\end{aligned}
$$

'Suddenly Yoni took the cherries and left.'

9 Some other adverbs, like the temporal adverbial yesterday (etmol) can in fact precede Wh/Q. Such adverbials have enough referential properties to make them natural candidates for topicalization, hence for movement to the higher Top position (Rizzi 2004), preceding Q. The fact that adverbs like yesterday can naturally move to Top captures their appearance before Wh elements, as in (i).

(i) (b- a- yeshiva) etmol, $\mathrm{mi}$ kam ve- halax?

(in-the-meeting) yesterday who stood_up and-left

'(In-the-meeting) yesterday, who stood up and left?'

In contrast, suddenly cannot naturally move to Top, this is what makes it a better candidate to examine the position of Mod.

10 Unlike classic (Germanic) V2, in Hebrew verb movement to Fin is not obligatory. It should be noted that in Samo's (2019) analysis of Germanic V2, the inflected verb moves to Fin and then continues to move to the relevant criterial head (Top, Q, Mod, etc.). If Samo's analysis is applied to Hebrew, the surface position of the inflected verb in inversion structures does not directly manifest Fin, but a criterial position higher than Fin. 
The same point can be made about $Q$ and Top. We can observe in (13) and (14) that the Wh element in (13) and the topic in (14) precede the preposed finite verb, in Fin, which precedes the subject. This order establishes that $\mathrm{Q}$ is higher than Fin and that Top is higher than Fin. (and, by transitivity, given that Int is higher than Top (7), Int is higher than Fin as well).

Q $>$ Fin

a. Argument question: Ma axla ha- yalda b- a- kikar? what ate the-girl in-the-square 'What did the girl in the square eat?'

b. Adjunct question: Eix osa para? how does cow 'What sound does a cow make?'

c. Embedded argument question: Ani toha ma axla ha- yalda b- a- kikar. I wonder what ate the-girl in-the-square 'I wonder what the girl ate in the square.'
Top > Fin
Et ha-glida axla ha- yalda be-teavon rav.
P.ACC the-ice.cream ate the-girl in-appetite much
'The girl ate the ice-cream with much appetite.'

Verb inversion is possible in Hebrew after the relative complementizer she- (15), establishing Force above Fin (relative complementizers are very high in the structure of the LP, in a position close, or identical to Force, Rizzi 1997; see a more detailed discussion on the analysis of relative clauses below in Section 4.3.1). Interestingly, as shown in (15'), inversion is impossible after the sentential embedding marker she-. We assume that the difference between the two types of shestems from the fact that in relative clauses, but not in sentential complements, there is a licenser passing through Spec Fin, the relativized phrase. Under the raising analysis of relative clauses, the relativized NP (the relative "head" in traditional terminology) moves through Spec-Fin, hence allowing the finite verb to move into the Fin head. In contrast, in sentential embedding, inversion is unavailable under the embedding marker she- because in sentential complements there is no movement involved, hence there is no passing through Spec-Fin, consequently the movement of the verb to Fin is not licensed. ${ }^{11,12}$

11 The distributional difference with respect to triggered inversion in she-clauses between relatives and embedded declaratives suggests that reducing declarative embedding to a form of relativization cannot be too direct, as one involves movement, and the other one apparently does not.

12 Another minimal pair illustrating the dependence on movement of V-to-Fin is provided by the contrast between topicalization structures and hanging topics (with a resumptive downstream). The first showing island sensitivity and connectivity effects, both hallmarks of movement, whereas the latter does not show such properties (and hence is analysed as a structure without movement). Verb inversion, V-to-Fin, occurs with the former, but not with the latter. As shown in the contrast between (i) and (ii), all meaning 'Dan met this friend in the garden.'

This can be explained if Spec,Fin has to be activated by movement.

Topicalization:

(i) Et ha- xaver ha- ze Dan pagash b- a- gan. P.ACC the-friend the-this Dan met in-the-garden

(i') Et ha- xaver ha- ze pagash Dan b-a- gan. P.ACC the-friend the-this met Dan in-the-garden

Hanging topic:

(ii) Ha- xaver ha- ze, Dan pagash ot- o b-a- gan. the-friend the-this, Dan met P.ACC-3SG.MAS in-the-garden

(II') *Ha- xaver ha- ze, pagash Dan ot- o b- a- gan. the-friend the-this, met Dan P.ACC-3SG.MAs in-the-garden 
Relative complementizer (Force) $>$ Fin

(15)

Relative complementizer

Ha- glida she- axla ha- yalda hayta yeruka.

the-ice.cream that-ate the-girl was green

'The ice-cream that the girl ate was green.'

\section{Embedding marker}

*Ani xoshev she- axla ha- yalda glida.

I think that-ate the-girl ice.cream

In conclusion, Fin is the lowest head within the LP, preceded by all other left peripheral positions identified, Force, Int, Top, Q, and Mod. The above empirical observations yield the order Force $>$ Int $>$ Top $>\mathbf{Q}>$ Mod $>$ Fin in the Hebrew LP. The emerging design of the tree is depicted in Figure 1.

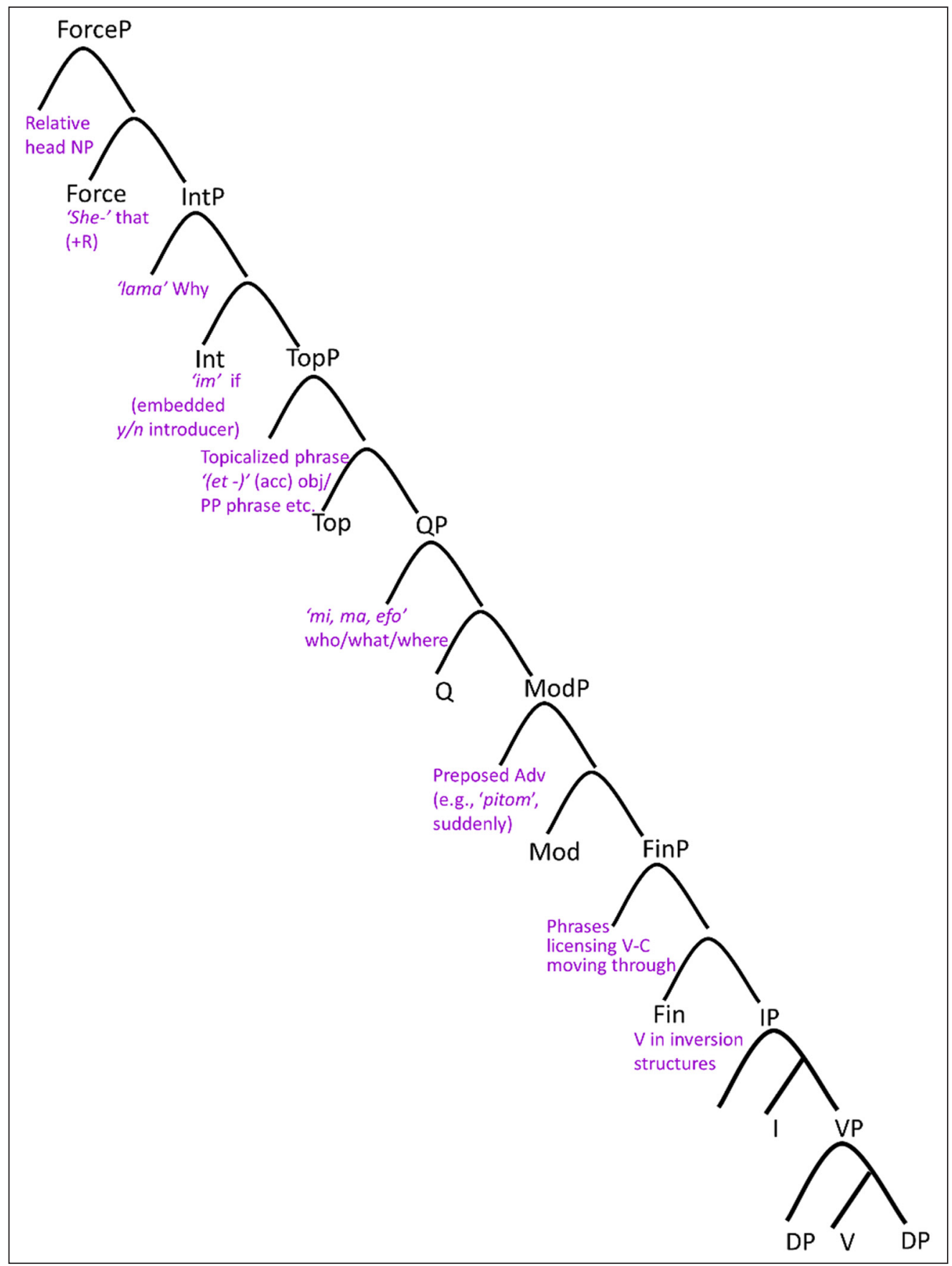

It is interesting to note that the order that emerges from the distributional evidence in Hebrew is essentially the same as the one found for Romance as in the schematic representation in (5) above, as well as cross-linguistically (Japanese, Saito 2012; African languages, Aboh 2004, and more). This is to be expected under uniformity guidelines (Chomsky 2001).
Figure 1 Map of the functional sequence of the clause in Hebrew. 


\section{The acquisition data}

We base our account on results reported in Friedmann and Reznick (this volume), in view of providing a theory-guided analysis. We therefore begin by a succinct summary of the relevant results from Friedmann and Reznick that we seek to explain in this paper (these results and many more, as well the methods used to obtain them are described in full detail in Friedmann and Reznick's paper, in this volume. See also Appendix A).

\subsection{Summary of Friedmann and Reznick's results}

Friedmann and Reznick examined the order of acquisition of various syntactic constructions in Hebrew, using a sentence repetition task in which 60 monolingual typically-developing Hebrewspeaking children aged 2;2-3;10 repeated 80 sentences each, and an analysis of the spontaneous speech of 61 (other) children aged 1;6-6;1 (56 who were recorded once and 5 whose longitudinal data were recorded and analysed), which included a total of 27,696 utterances.

The sentence repetition task included structures with A-movement, which were sentences with unaccusative verbs in SV order, three types of sentences derived by A-bar movement: subject relatives, object relatives, and topicalization structures, and sentences involving verb inversion in adverb-VS order with unergative and transitive verbs. The test also included SV sentences with unergative and transitive verbs, which were matched in words, length and number of words to the structures with movement, in order to control for extra-linguistic cognitive factors such as memory and attention (for more details see Friedmann \& Lavi 2006). The spontaneous speech analysis encompassed a very wide variety of sentence structures. In the current analysis, we focus on SV sentences with unergative/transitive verbs, VS and SV sentences with unaccusatives, Wh questions of various types, relative clauses, topicalization structures, and finite embedded sentences. Following predictions emerging from our new account, we also analyze root yes/no questions, why questions, and preposed adverbs

Data gathered through both methodologies were analyzed using the concept of Guttman scale (Guttman 1944; 1950), which revealed the order of acquisition of the various structures. Guttman scales allow for the identification of implicational relations between properties. For example, if properties A and B are organized in a Guttman scale, then if property B is there, property A has to be there as well, but the implication does not necessarily hold in the opposite direction: if property A is there, B may or may not be there. For example, if an exam includes a hard question that requires mastery of three areas of knowledge, a person who answered this question correctly would probably be able to answer a question that involves just two of the three areas. A person who answers correctly a question that requires mastery of two areas would probably be able to answer a question that requires only one of the areas. This creates a Guttman scale between the three questions. Another example may come from number cognition - a child who can count to 100 would also be able to count to 10 . A child who can count to 10 would also be able to count to 4 . The other direction would obviously not work: not all children who can count to 4 can also count to 10 or 100 . These three levels of capacity form a Guttman scale.

In these examples, one capacity includes the other as a subpart, or implies the other. There is a conceptual parallelism between the growing trees logic and the Guttman scale. If we think of structure building as occurring from lower to higher layers, under the growing trees view, higher parts of the tree necessarily include lower parts, and the acquisition of the higher parts would necessarily imply the acquisition of the lower ones.

Figure 2, reproduced from Friedmann \& Reznick, provides a summary of the findings by these authors, and represents the take-off point for our Growing Trees approach. On the left is the Guttman scale produced from the analysis of the spontaneous speech samples, and on the right is the Guttman scale yielded from the repetition of the various types of movement.

The sentence repetition task revealed a set order of acquisition of three types of syntactic movement: the first structures to be mastered (i.e., at least $80 \%$ of the sentences repeated correctly) are A-movement (of the internal argument of unaccusative verbs to subject position) together with simple SVO sentences, then A-bar-movement to the left periphery (represented in the repetition task by relative clauses and topicalization structures) are mastered, and finally comes movement of the lexical main verb from I to C. Relative clauses and topicalization structures were acquired 


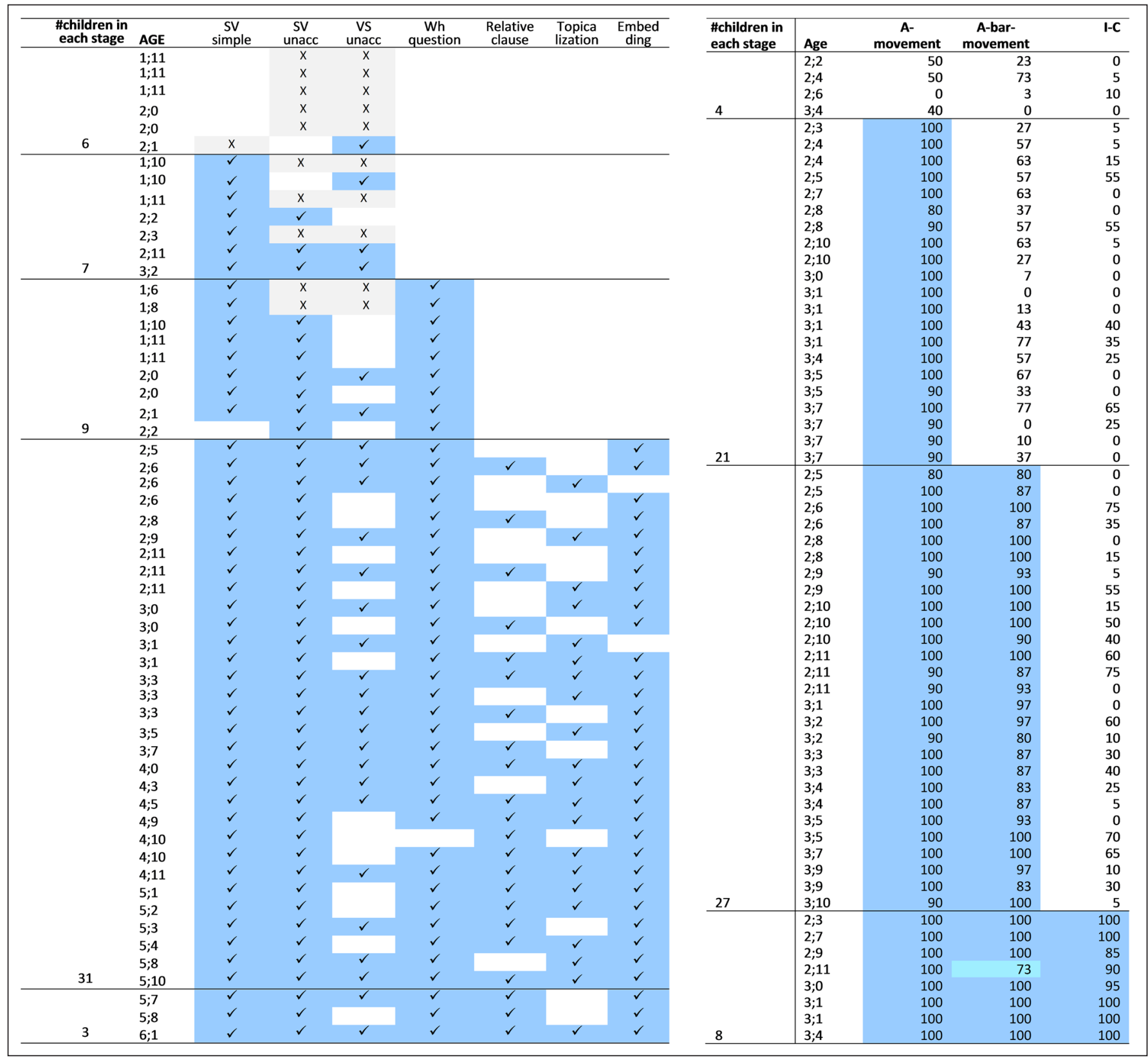

together. There was no correlation with age. Crucially, the order of acquisition forms a perfect Guttman scale, as summarized in Figure 2: four children were unable to repeat any structure; 21 children were able to repeat sentences with A-movement but not sentences with A-bar or I-to-C movements; 27 children could repeat both A- and A-bar movement structures, but not I-to-C structures; and 8 children could repeat all three structures: sentences with A-movement, A-bar movement, and I-to-C movement. There was no child who could repeat I-to-C but not A- and A-bar movement, and no child who could repeat A-bar movement but not A-movement. ${ }^{13}$

The analysis of spontaneous speech revealed the same order of acquisition, and provided further insights into the order of acquisition within the group of constructions with A-barmovement, and their relation to the acquisition of sentence embedding. Similarly to the repetition

13 We do not discuss further the late acquisition of I-to-C, as documented in Friedmann \& Reznick (this volume, as well as Zuckerman 2001; Friedmann 2007; Friedmann \& Costa 2011). It seems that although children are exposed to such structures quite often, especially in written register, for instance when they hear children's books, they do not produce them until quite late. We tentatively suggest that because sentences with I-to-C Inversion in Hebrew are typical of a certain, literary register which may be anchored in a high position in the LP, the acquisition of these structures is delayed until such register is acquired (and the related high position as well). We note, though, that I-to-C Inversion is also used in certain non-high-register sentences, such as "Eix osa para?" (how does cow, 'what sound does a cow make?'), “Eix hayta ha-uga?" (how was the-cake, 'How was the cake?') and indeed, 4 of the children (who were all in Stage 2 of the stages discussed below) produced a few instances of these structures. Given the limited amount of relevant evidence, we do not engage in this paper in a proposal at this point, and leave the whole issue of the late acquisition of I-to-C for future work.
Figure 2 A summary of the findings from Friedmann \& Reznick (this volume): Production profiles of various structures, ordered by stage of acquisition giving rise to a Guttman scale. Left: spontaneous speech samples. Right: sentence repetition (\%correct). Blue (dark shaded) cell: the child masters the structure (in repetition: at least $80 \%$ of the sentences of this structure were repeated correctly; in spontaneous speech: at least one such structure appeared in the child's sample). Grey (lightly shaded) cell: the sample did not include a relevant verb. Reproduced from Friedmann \& Reznick (this volume). 
task, age was not a good predictor of the acquisition of the various syntactic structures, as different children acquired the same structure in different ages, but the order of acquisition was uniform across children irrespective of their age: 1) A-movement of the internal argument of unaccusative verbs to subject position appears first - first occurrence in the corpus at age 1;10 (and 1;7 in the longitudinal data). (From age 2;2 all children who produced an unaccusative verb also used SV order with it). SV order with unaccusative verbs appeared together with simple sentences in SV(O) order with unergative and transitive verbs; 2) The next instances of movement to appear are argument Wh questions, i.e., subject- and object questions, including object questions inquiring about the verb phrase ('what are you doing') and some adjunct Wh questions (e.g., where), with no difference between subject and object questions or between argument and adjunct questions (of the types that appeared at that stage) - Wh questions first occur in the analyzed corpus at age $1 ; 6$, stabilizing at age $2 ; 5$ (by "stabilizing" we mean that more than $80 \%$ of the children already used them, in this case $92 \%$ of the children used Wh questions from age 2;5); 3) In the next stage, relative clauses (headed and free relatives), and topicalization structures appear together, again with no difference between subject and object dependencies. Importantly, this stage is concomitant to the appearance of sentence embedding of both declarative and interrogative embedded clauses. (Notice that we discuss here only adultlike embedding, and not other forms such as so-called "preconjunctionals", Penner \& Mueller 1992). These structures first appear at age 2;5-2;6 and stabilize between the ages 3;3 and 4;0 years; 4) Last comes movement of the lexical verb (beyond "do", see footnote 13) to C, which appeared only in three children, the youngest of whom was 5;7.

Here, too, the Guttman scale was very robust, with 6 children showing none of the structures; 7 showing simple SV with unergative and transitive verbs, and SV, as well as VS, with unaccusative verbs; 9 children who produced SV sentences as well as Wh questions; 34 who produced SV sentences, Wh questions, as well as relative clauses/topicalization/embedded clauses. (Three of these 34 children, the bottom 3 in Figure 2, produced all the above as well as I-to-C sentences with a lexical verb.) Only a single child of the 56 did not conform to the Guttman scale, as his sample included relative clauses and embedded clauses but no Wh questions.

\subsection{New questions emerging from the data}

The results from the spontaneous speech analyses and from the repetition task yield a converging picture regarding stages of acquisition: SV structures, including those derived by A-movement with unaccusative verbs, are acquired first, then Wh questions are acquired, and then relative clauses, topicalization structures, and sentential embedding structures are acquired together.

The three stages emerge in a robust and crystal-clear manner, as shown by the fact that the relevant clusters of constructions can be neatly organized in Guttman scales. These results raise further theoretical questions, though:

1. Why does A-movement, illustrated by SV order with unaccusative verbs, occur before any instance of A-bar movement?

2. Why are Wh questions acquired about one year (with individual variation) before other A-bar structures such as relative clauses and topicalization?

3. Why are topicalization, relative clauses, and clausal embedding acquired at the same time?

It is hard to capture the three structures mentioned in question 3, topicalization, relative clauses, and clausal embedding, as a natural class in terms of properties like embedding and movement: two (relative clauses and sentential embedding) are embedded structures and the other is not; two (topicalization and relative clauses) involve movement, but the other does not.

Our goal in the present paper is to provide a principled basis for the analysis of the three stages, also addressing the puzzles just mentioned. The key ingredient is the cartographic representation, which offers a fine-grained hierarchical structure detailed enough to draw the required distinctions. We propose a "Growing Trees" approach by which the map of the left periphery is acquired gradually, starting from the lower layers, and then moving to higher layers.

In the next section (Section 3) we present our Growing Trees account and show how it captures the three stages emerging from Friedmann and Reznick (this volume) just described. We then discuss each stage in detail (Sections 4.1-4.3) and illustrate further predictions that can be derived from the cartographic map and examine them empirically through further analyses 
of the corpus. These cartographically-guided analyses will allow us to investigate further the difference in acquisition of root and embedded questions (Section 4.3.1), address the status of yes/no questions compared to Wh questions (Section 4.2.2), and revisit the acquisition of why compared to other types of Wh questions (Section 4.3.2.1). The approach will also allow us to suggest an analysis of the stage of acquisition of sentence-initial adverbs (Sections 4.2 .1 and 4.3.2.2). In Section 4.4 we show how the findings replicate in longitudinal data. The approach also predicts no asymmetry in production between subject- vs. object relatives, and subject- vs. object questions, such lack of difference is indeed found in the data (Section 4.5). We conclude Section 4 with an open question regarding a possible stage preceding Stage 1 (Section 4.6).

\section{The Growing Trees account}

At the heart of our approach to the stages of structure acquisition that emerge from both the repetition study and the analysis of the spontaneous speech corpus is the idea that the stages correspond to specific zones of functional layers in the cartographic tree. Each stage of acquisition corresponds to a larger and larger part of the tree. The lower parts of the tree are acquired first, and then higher and higher parts are gradually acquired.

We ascribe the three stages identified in Friedmann \& Reznick (this volume) to three stages depicted on the syntactic tree in Figure 3. An important difference is that whereas Friedmann \& Reznick (this volume) mainly referred to different types of movement (A-movement, A-bar movement, and I-C movement), we refer here to positions in the tree. We propose that what crucially determines whether different movement types are acquired is whether the layer of

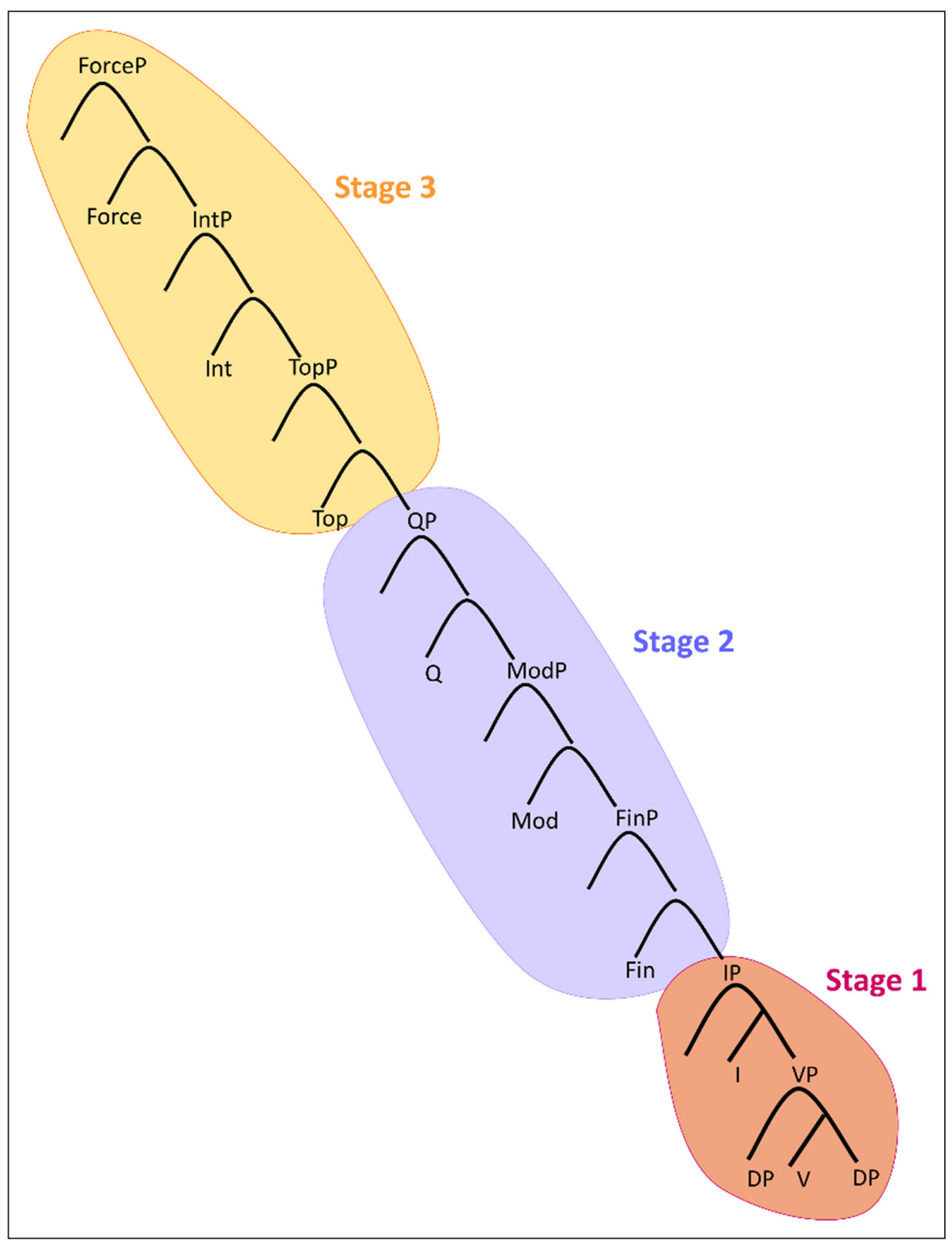


the syntactic tree supporting the position implicated in this movement has been acquired. Cast in cartographic terms, this would correspond to the mastery of the properties of the heads containing the features triggering the different movements.

In Stage 1 children have bare IPs, which include the triggering head of A-movement. Therefore, at this stage, they master A-movement of the internal argument of unaccusative verbs to subject position. At the same stage, the children have acquired simple sentences in SV order with unergative and transitive verbs, which under current assumptions also involve movement of the subject from the thematic position internal to the VP to the subject position of the clause in spec IP.

In Stage 2, the lower field of the left periphery becomes available. A crucial point for accounting for the pattern of acquisition that emerged from the spontaneous speech was that different A-bar structures were acquired in separate stages. Wh questions are acquired before relative clauses and topicalization. This becomes readily explained by looking at the cartographic tree (See Figure 1 above): whereas root Wh questions involve movement to a lower layer in the LP related to the Q head, relative clauses and topicalization structures involve movement to much higher layers within the LP related to the higher Force and Top heads. Thus, the different layers supported by the various heads identify zones of the left periphery, to which we will also refer as "fields". A generalization according to which the lower field of the LP is acquired first, explains the finding that root Wh questions are acquired before relative clauses and topicalization structures. Therefore, Stage 2 is the stage in which root Wh questions are acquired, including argument (subject and object) questions, and some adjunct questions.

In Stage 3, the next stage of the growing tree, the higher field of the left periphery becomes available. This allows for relative clauses and topicalization structures to appear, together with clausal embedding (both declarative and interrogative embedded clauses). Again, the description in terms of zones of the cartographic tree provides an immediate account for the concurrent appearance of relative clauses and embedding together with root topicalization structures (under the assumption of an appropriate selection mechanism for embedded clauses, on which see below).

These stages, we believe, develop following a maturational schedule. This is consistent with the finding that age is not a good predictor of structure acquisition. Just like other biological maturational properties (teething, puberty), the stages apply to all children, but the ages in which these stages are realized greatly differ. Thus, for example, in the corpus there is an 18 months old child who is already at Stage 2, whereas another child who is 26 months old is still at Stage 1. One can say that the 18 months old child reached the maturational stage that allowed her to already project Stage 2 structures, whereas the 26 months old child was still at an earlier point in the maturational schedule.

We now discuss each of these stages in more detail, derive new predictions from the theory and examine them empirically, and then discuss a further stage of development of a different kind, which follows the completion of the acquisition of the entire clausal tree structure.

\section{The three stages in detail}

\subsection{Stage 1. VP and IP}

In Stage 1, children have acquired VP and IP (see Figure 4), and this enables them to get the SV order with unaccusative verbs (in addition to the VS order). Given the unaccusative hypothesis (Perlmutter 1978; Burzio 1986), SV order with unaccusative verbs involves movement of the internal argument from its thematic position. The availability of I, endowed with attracting features, makes spec IP available, and allows the children to move the DP from the thematic position internal to the VP to the subject position of the clause in spec IP.

The existence of SV order with unaccusative verbs, then, provides explicit evidence for A-movement. The occurrence of this structure in our Stage 1 supports the view that A-movement is available from early stages (as claimed in Pierce 1992; Snyder et al. 1995; Sano et al. 2001; Adragão \& Costa 2004; Lorusso et al. 2005; Friedmann 2007; Shimada \& Sano 2007; Costa \& 


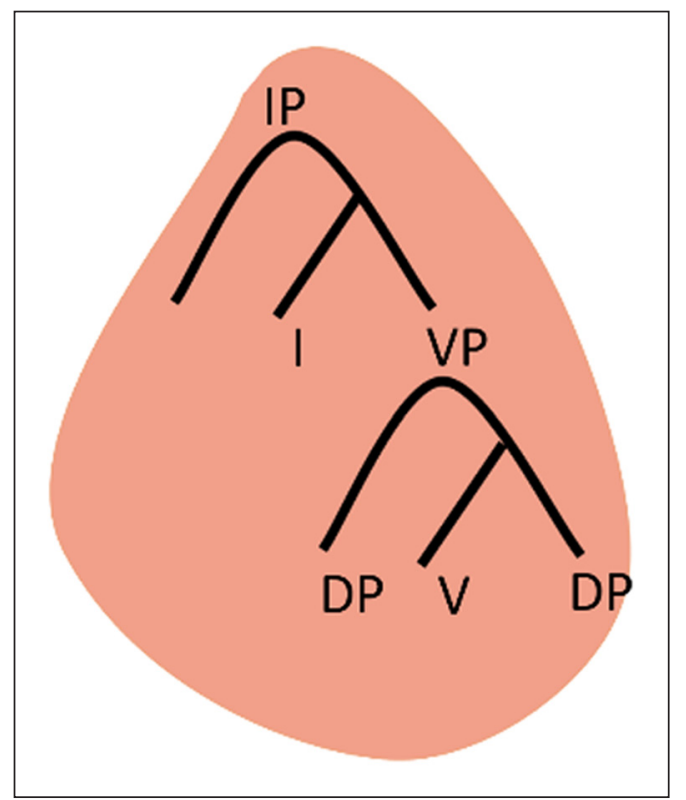

Friedmann 2009; 2012; Friedmann \& Costa 2011; and contra approaches like Borer \& Wexler 1987; Babyonyshev et al. 2001; Machida et al. 2004; Wexler 2004).

In the data of children who are at Stage 1 we see that they produce unaccusative verbs in both SV and VS orders. The data in our corpus also provide direct evidence that children distinguish between unaccusatives on the one hand and unergatives (and transitives) on the other. At this stage, only with unaccusatives do we also find the VS order, which is the order of merge according to the unaccusative hypothesis (Perlmutter 1978; Perlmutter \& Postal 1984; Burzio 1986; Belletti 1988). It is only at Stage 3 (or later) that we find VS order with unergatives and transitives, which, in Hebrew, is a function of I-to-C movement. This finding is in line with data from Italian, Hebrew, and European Portuguese showing early access to the identification of the unaccusative class, and the distinction between unaccusative and unergative verbs (Adragão \& Costa 2004; Lorusso et al. 2005; Friedmann 2007; Costa \& Friedmann 2009; 2012; Belletti \& Guasti 2015; Belletti \& Bianchi 2016).

Another consideration is relevant here. Chomsky (1995; 2000) traced back movement to the fundamental structure-building mechanism. Structure building that incorporates an element from outside the structure is "external Merge", and structure building that uses internal building blocks - elements that have already been incorporated into the tree - are instances of "internal Merge"; internal Merge is commonly referred to as "movement". This approach suggests, then, that movement and structure building are fundamentally the same: both are instances of Merge. ${ }^{14}$ Our data is consistent with this unified view of Merge, as we could not identify a "pre-movement" stage, in which structure building is available, but movement is not yet acquired (see our further discussion of this point in Section 4.6).

\subsection{Stage 2. The lower field of the left periphery}

From Stage 2 on, we start seeing evidence that part of the structure of the left periphery became available (See Figure 5). The first manifestation of movement to the LP is the early production of Wh questions. Given current cartographic analyses of different languages (see Rizzi 1997 footnote 4; Rizzi \& Cinque 2016; Rizzi \& Bocci 2017), the lower part of this LP configuration includes the landing site of argument- (and some adjunct-) Wh questions. This appears to be valid for Hebrew as well, as shown in Section 1.1, see Figure 1. Hence, under the Growing Trees account, the occurrence of Wh questions is expected as soon as the relevant part, the lower part of the left periphery, becomes available, in Stage 2.
Figure 4 Stage 1 of the growing tree. 


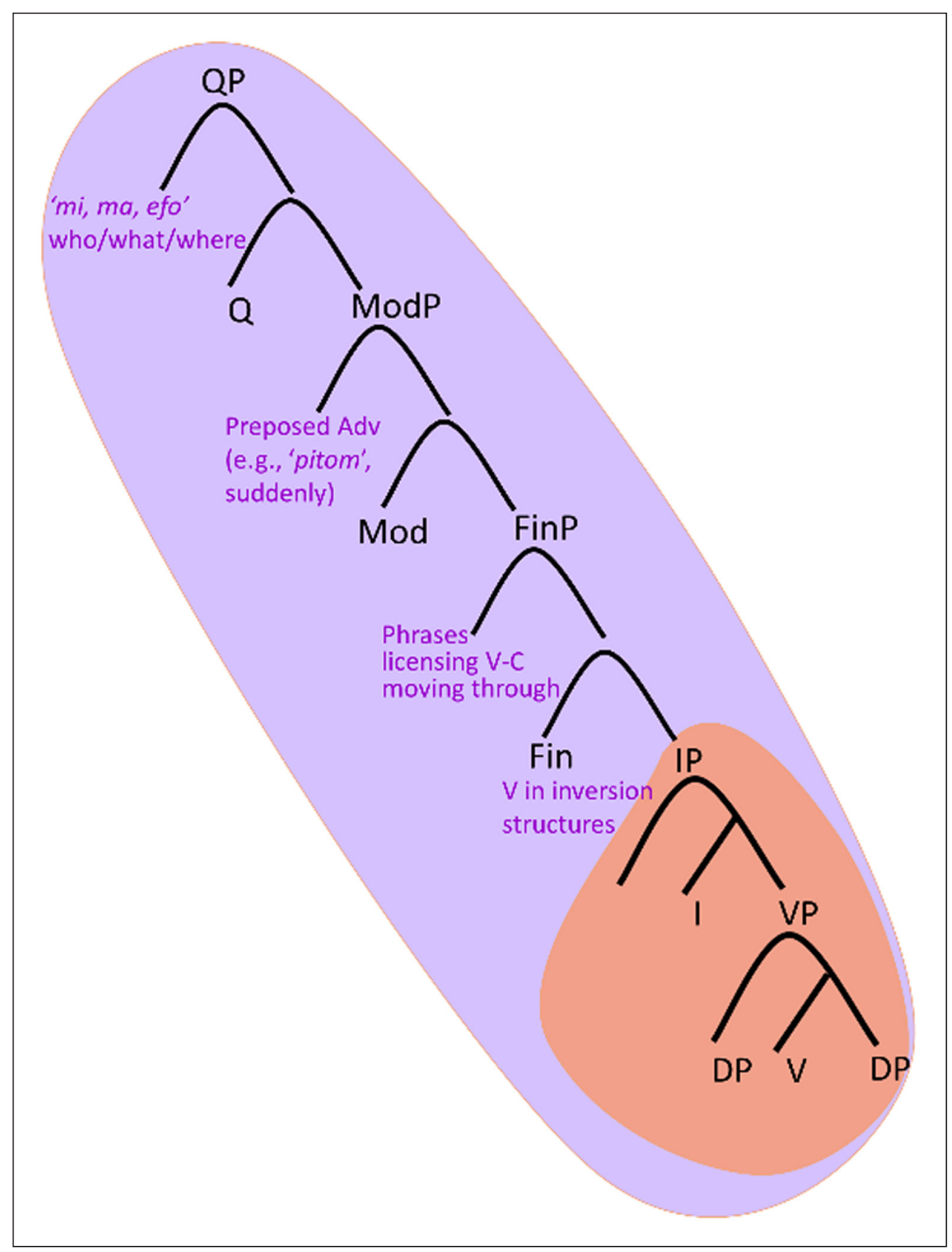

At this stage, the children produced root argument Wh questions of various kinds: subject, object, PP object, object questions inquiring about the verb phrase ('what are you doing?'), as well as adjunct where (and a few where-to and when) questions. All these questions appeared at the same stage, without difference between subject and object questions (for similar findings regarding no difference between subject and object questions in early acquisition see Eyal 1976; Stromswold 1995).

\subsubsection{From acquisition data to linguistic analysis: Preposed adverbs}

Another head that is included in the map of the lower field is Mod. If preposed adverbs move to spec-Mod, then we expect them to also appear in Stage 2, together with Wh questions. And this is precisely what our data show: of the 12 children who were at Stage 2, five indeed produced sentences with preposed adverbs (see example (16); none of the Stage 1 children did). Table 1 summarizes all the data analyzed for the three stages, column "preposed adv" lists the appearance of preposed adverbs for each of the analysed samples. 
Table 1 The acquisition of the various structures organized by stage in which the structure is acquired, and ordered by the stage in which each child has acquired it (rather than by age). Each row summarizes the production of a different child, a blue (shaded) cell indicates that the child produced this structure; a white (unshaded) cell indicates that the child did not produce any instance of this structure; a grey cell means that the corpus of this child did not include any verb of the relevant type (for example, the corpus did not include any unaccusative verb).

\begin{tabular}{|c|c|c|c|c|c|c|c|c|c|c|c|}
\hline \multirow[b]{2}{*}{$\begin{array}{c}\text { Age } \\
\text { (months) }\end{array}$} & \multicolumn{3}{|c|}{$\begin{array}{l}\text { STAGE 1: } \\
\text { VP+IP Structures }\end{array}$} & \multicolumn{4}{|c|}{$\begin{array}{l}\text { STAGE 2: } \\
\text { low CP zone structures }\end{array}$} & \multicolumn{4}{|c|}{$\begin{array}{l}\text { STAGE 3: } \\
\text { high CP zone structures }\end{array}$} \\
\hline & $\begin{array}{c}\text { SV } \\
\text { simple }\end{array}$ & $\begin{array}{c}\text { SV } \\
\text { unacc }\end{array}$ & $\begin{array}{c}\text { VS } \\
\text { unacc }\end{array}$ & $\begin{array}{l}\text { Root Wh } \\
\text { argument }\end{array}$ & $\begin{array}{l}\text { Wh adjunct } \\
\text { excl why }\end{array}$ & $\begin{array}{l}\text { Prepos } \\
\text { ed Adv }\end{array}$ & $\begin{array}{l}\text { Root } \\
\mathrm{y} / \mathrm{n}\end{array}$ & Why & $\begin{array}{l}\text { Relative } \\
\text { clause }\end{array}$ & $\begin{array}{l}\text { Topica } \\
\text { lization }\end{array}$ & $\begin{array}{l}\text { Embe } \\
\text { dding }\end{array}$ \\
\hline 23 & 0 & 0 & 0 & 0 & 0 & 0 & 0 & 0 & 0 & 0 & 0 \\
\hline 23 & 0 & 0 & 0 & 0 & 0 & 0 & 0 & 0 & 0 & 0 & 0 \\
\hline 23 & 0 & 0 & 0 & 0 & 0 & 0 & 0 & 0 & 0 & 0 & 0 \\
\hline 24 & 0 & 0 & 0 & 0 & 0 & 0 & 0 & 0 & 0 & 0 & 0 \\
\hline 24 & 0 & 0 & 0 & 0 & 0 & 0 & 0 & 0 & 0 & 0 & 0 \\
\hline 25 & 0 & 0 & $\checkmark$ & 0 & 0 & - & - & 0 & 0 & 0 & 0 \\
\hline 22 & $\checkmark$ & 0 & $\checkmark$ & 0 & 0 & - & - & 0 & 0 & 0 & 0 \\
\hline 22 & $\checkmark$ & No unacc $V$ & No unacc V & 0 & 0 & - & - & 0 & 0 & 0 & 0 \\
\hline 23 & $\checkmark$ & No unacc V & No unacc $V$ & 0 & 0 & 0 & 0 & 0 & 0 & 0 & 0 \\
\hline 26 & $\checkmark$ & $\checkmark$ & 0 & 0 & 0 & 0 & 0 & 0 & 0 & 0 & 0 \\
\hline 18 & $\checkmark$ & 0 & 0 & $\checkmark$ & $\checkmark$ & 0 & $\checkmark$ & 0 & 0 & 0 & 0 \\
\hline 20 & $\checkmark$ & 0 & 0 & $\checkmark$ & $\checkmark$ & 0 & $\checkmark$ & 0 & 0 & 0 & 0 \\
\hline 22 & $\checkmark$ & $\checkmark$ & 0 & $\checkmark$ & 0 & - & $\checkmark$ & 0 & 0 & 0 & 0 \\
\hline 23 & $\checkmark$ & $\checkmark$ & 0 & $\checkmark$ & 0 & - & - & 0 & 0 & 0 & 0 \\
\hline 23 & $\checkmark$ & $\checkmark$ & 0 & $\checkmark$ & $\checkmark$ & $\checkmark$ & $\checkmark$ & 0 & 0 & 0 & 0 \\
\hline 24 & $\checkmark$ & 0 & $\checkmark$ & $\checkmark$ & $\checkmark$ & 0 & $\checkmark$ & 0 & 0 & 0 & 0 \\
\hline 24 & $\checkmark$ & No unacc V & No unacc $V$ & $\checkmark$ & 0 & - & - & 0 & 0 & 0 & 0 \\
\hline 25 & $\checkmark$ & $\checkmark$ & $\checkmark$ & $\checkmark$ & $\checkmark$ & $\checkmark$ & $\checkmark$ & 0 & 0 & 0 & 0 \\
\hline 26 & 0 & $\checkmark$ & 0 & $\checkmark$ & 0 & $\checkmark$ & $\checkmark$ & 0 & 0 & 0 & 0 \\
\hline 27 & $\checkmark$ & No unacc V & No unacc $V$ & 0 & 0 & 0 & $\checkmark^{\mathrm{a}}$ & 0 & 0 & 0 & 0 \\
\hline 35 & $\checkmark$ & $\checkmark$ & $\checkmark$ & $\checkmark^{b}$ & 0 & $\checkmark$ & $\checkmark$ & 0 & 0 & 0 & 0 \\
\hline 38 & $\checkmark$ & $\checkmark$ & $\checkmark$ & 0 & 0 & $\checkmark$ & 0 & 0 & 0 & 0 & 0 \\
\hline 29 & $\checkmark$ & $\checkmark$ & $\checkmark$ & 0 & $\checkmark$ & $\checkmark$ & $\checkmark$ & $\checkmark$ & 0 & 0 & $\checkmark$ \\
\hline 30 & $\checkmark$ & $\checkmark$ & $\checkmark$ & $\checkmark$ & $\checkmark$ & $\checkmark$ & $\checkmark$ & 0 & $\checkmark$ & 0 & $\checkmark$ \\
\hline 30 & $\checkmark$ & $\checkmark$ & $\checkmark$ & $\checkmark$ & $\checkmark$ & $\checkmark$ & 0 & 0 & 0 & $\checkmark$ & 0 \\
\hline 30 & $\checkmark$ & $\checkmark$ & 0 & $\checkmark$ & $\checkmark$ & $\checkmark$ & 0 & 0 & 0 & 0 & $\checkmark$ \\
\hline 32 & $\checkmark$ & $\checkmark$ & 0 & $\checkmark$ & 0 & $\checkmark$ & 0 & 0 & $\checkmark$ & 0 & $\checkmark$ \\
\hline 33 & $\checkmark$ & $\checkmark$ & $\checkmark$ & $\checkmark$ & 0 & $\checkmark$ & $\checkmark$ & 0 & 0 & 0 & $\checkmark$ \\
\hline 35 & $\checkmark$ & $\checkmark$ & 0 & $\checkmark$ & $\checkmark$ & $\checkmark$ & $\checkmark$ & $\checkmark$ & 0 & 0 & $\checkmark$ \\
\hline 35 & $\checkmark$ & $\checkmark$ & $\checkmark$ & $\checkmark$ & $\checkmark$ & $\checkmark$ & $\checkmark$ & $\checkmark$ & $\checkmark$ & 0 & $\checkmark$ \\
\hline 35 & $\checkmark$ & $\checkmark$ & 0 & $\checkmark$ & $\checkmark$ & $\checkmark$ & $\checkmark$ & $\checkmark$ & 0 & $\checkmark$ & $\checkmark$ \\
\hline 36 & $\checkmark$ & $\checkmark$ & $\checkmark$ & $\checkmark$ & $\checkmark$ & $\checkmark$ & $\checkmark$ & 0 & 0 & $\checkmark$ & $\checkmark$ \\
\hline 36 & $\checkmark$ & $\checkmark$ & 0 & $\checkmark$ & $\checkmark$ & $\checkmark$ & $\checkmark$ & 0 & $\checkmark$ & 0 & $\checkmark$ \\
\hline 37 & $\checkmark$ & $\checkmark$ & $\checkmark$ & $\checkmark$ & $\checkmark$ & $\checkmark$ & $\checkmark$ & 0 & 0 & $\checkmark$ & 0 \\
\hline 37 & $\checkmark$ & $\checkmark$ & 0 & $\checkmark$ & $\checkmark$ & $\checkmark$ & $\checkmark$ & $\checkmark$ & $\checkmark$ & 0 & $\checkmark$ \\
\hline 39 & $\checkmark$ & $\checkmark$ & $\checkmark$ & $\checkmark$ & $\checkmark$ & $\checkmark$ & $\checkmark$ & 0 & $\checkmark$ & $\checkmark$ & $\checkmark$ \\
\hline 39 & $\checkmark$ & $\checkmark$ & $\checkmark$ & $\checkmark$ & $\checkmark$ & $\checkmark$ & 0 & $\checkmark$ & 0 & $\checkmark$ & $\checkmark$ \\
\hline 39 & $\checkmark$ & $\checkmark$ & $\checkmark$ & $\checkmark$ & $\checkmark$ & $\checkmark$ & $\checkmark$ & 0 & $\checkmark$ & 0 & $\checkmark$ \\
\hline 41 & $\checkmark$ & $\checkmark$ & $\checkmark$ & $\checkmark$ & $\checkmark$ & $\checkmark$ & $\checkmark$ & $\checkmark$ & 0 & $\checkmark$ & $\checkmark$ \\
\hline 43 & $\checkmark$ & $\checkmark$ & $\checkmark$ & $\checkmark$ & $\checkmark$ & $\checkmark$ & $\checkmark$ & $\checkmark$ & $\checkmark$ & 0 & $\checkmark$ \\
\hline 48 & $\checkmark$ & $\checkmark$ & $\checkmark$ & $\checkmark$ & $\checkmark$ & $\checkmark$ & $\checkmark$ & $\checkmark$ & $\checkmark$ & $\checkmark$ & $\checkmark$ \\
\hline 51 & $\checkmark$ & $\checkmark$ & $\checkmark$ & $\checkmark$ & $\checkmark$ & $\checkmark$ & $\checkmark$ & $\checkmark$ & 0 & $\checkmark$ & $\checkmark$ \\
\hline 53 & $\checkmark$ & $\checkmark$ & $\checkmark$ & $\checkmark$ & $\checkmark$ & $\checkmark$ & $\checkmark$ & $\checkmark$ & $\checkmark$ & 0 & $\checkmark$ \\
\hline 57 & $\checkmark$ & $\checkmark$ & 0 & $\checkmark$ & $\checkmark$ & 0 & $\checkmark$ & 0 & $\checkmark$ & 0 & $\checkmark$ \\
\hline 58 & $\checkmark$ & $\checkmark$ & 0 & 0 & 0 & $\checkmark$ & 0 & 0 & $\checkmark$ & 0 & $\checkmark$ \\
\hline 58 & $\checkmark$ & $\checkmark$ & 0 & $\checkmark$ & $\checkmark$ & $\checkmark$ & $\checkmark$ & $\checkmark$ & $\checkmark$ & $\checkmark$ & $\checkmark$ \\
\hline 59 & $\checkmark$ & $\checkmark$ & $\checkmark$ & $\checkmark$ & $\checkmark$ & $\checkmark$ & $\checkmark$ & $\checkmark$ & $\checkmark$ & $\checkmark$ & $\checkmark$ \\
\hline 61 & $\checkmark$ & $\checkmark$ & 0 & $\checkmark$ & $\checkmark$ & 0 & $\checkmark$ & $\checkmark$ & $\checkmark$ & $\checkmark$ & $\checkmark$ \\
\hline 62 & $\checkmark$ & $\checkmark$ & 0 & $\checkmark$ & 0 & $\checkmark$ & $\checkmark$ & 0 & $\checkmark$ & $\checkmark$ & $\checkmark$ \\
\hline 63 & $\checkmark$ & $\checkmark$ & $\checkmark$ & $\checkmark$ & $\checkmark$ & $\checkmark$ & $\checkmark$ & $\checkmark$ & $\checkmark$ & 0 & $\checkmark$ \\
\hline 64 & $\checkmark$ & $\checkmark$ & 0 & $\checkmark$ & $\checkmark$ & $\checkmark$ & $\checkmark$ & $\checkmark$ & $\checkmark$ & $\checkmark$ & $\checkmark$ \\
\hline 67 & $\checkmark$ & $\checkmark$ & $\checkmark$ & $\checkmark$ & $\checkmark$ & $\checkmark$ & $\checkmark$ & 0 & $\checkmark$ & 0 & $\checkmark$ \\
\hline 68 & $\checkmark$ & $\checkmark$ & $\checkmark$ & $\checkmark$ & $\checkmark$ & $\checkmark$ & 0 & 0 & $\checkmark$ & 0 & $\checkmark$ \\
\hline 68 & $\checkmark$ & $\checkmark$ & $\checkmark$ & $\checkmark$ & $\checkmark$ & $\checkmark$ & $\checkmark$ & $\checkmark$ & 0 & $\checkmark$ & $\checkmark$ \\
\hline 70 & $\checkmark$ & $\checkmark$ & $\checkmark$ & $\checkmark$ & $\checkmark$ & $\checkmark$ & $\checkmark$ & $\checkmark$ & $\checkmark$ & 0 & $\checkmark$ \\
\hline 73 & $\checkmark$ & $\checkmark$ & $\checkmark$ & $\checkmark$ & $\checkmark$ & $\checkmark$ & $\checkmark$ & 0 & $\checkmark$ & $\checkmark$ & $\checkmark$ \\
\hline
\end{tabular}

- missing data point, $\checkmark$ : the structure appeared at least once in the child's sample. 0 : the child did not produce any instance of this structure.

${ }^{a}$ two yes/no questions, both of them ungrammatical (one with duplication of the verb, the other with inappropriate verb template), so this child may still be at Stage 1 rather than Stage 2.

${ }^{b}$ Only wh-DP question which may be formulaic. 


\subsubsection{From acquisition data to linguistic analysis: The derivation of yes/no questions}

As we discussed above, acquisition data may shed light on theoretical questions. The observed properties of the acquisition of Stage 2 provides a case in which data from acquisition may inform theory, here pertaining to the derivation of yes/no questions.

In principle, three possibilities exist with respect to the representation of the yes/no feature in the syntactic tree: no feature in the LP, a feature in Q, or a feature in Int. If the language allows for yes/no questions without an overt morpho-syntactic yes/no marker, and the interrogative interpretation is uniquely expressed through a special intonation at $\mathrm{PF}$, one conceivable option would be that there is no yes/no feature in the LP: the assignment of a special intonational contour could be triggered by an IP-internal featural specification. A second possibility is that the yes/no feature resides where the Wh operator resides, in Q, which is in the lower field of LP. A third option is that the yes/no feature in main questions resides where it resides in embedded yes/no questions, in Int, in the higher LP zone (Figure 1).

A way to inform the decision between the three options would be to examine whether yes/no questions are acquired with declarative SV sentences (which would support the no-feature-inthe-LP option), with root Wh questions (which would support the feature-in-Q option), or with embedded yes/no questions (supporting the feature-in-Int option).

In order to address this question, we conducted an analysis of the corpus used in Friedmann \& Reznick (this volume), with the same method. Using speech samples of 56 children (for detailed description of the methodology for data selection and analysis see Appendix A), we analysed, for each child, the structures that were already present in their sample, and looked for a hierarchy of acquisition of the various structures between children. In the logic of Guttman scales, if we found that there were samples that included only structure A, samples that included structures A and B, but no samples that included only B, we could conclude that $\mathrm{A}$ is acquired before $\mathrm{B}$.

The results, summarized in Tables 1 and 2, were that yes/no questions appeared later than declarative SV sentences, earlier than embedded yes/no questions, whereas we could not determine any order of precedence between yes/no questions and root Wh questions: in the samples of the 56 children in Table 1, none of the children in Stage 1 produced yes/no questions (neither did they produce wh questions), and 9 of the children in Stage 2, the stage in which Wh questions appear, produced yes/no questions without any indication of the higher LP (no relative clause, topicalization, or embedding, and crucially, no embedded Wh question). This suggests that yes/no questions are acquired at Stage 2, together with root Wh questions. Is there any order of precedence between Wh and yes/no questions? The data, summarized in Table 2, indicated no precedence between the two, namely, there was no Guttman scale for Wh and yes/no questions. All but one of the ten children in Stage 2 for whom we had raw data for analysis of this issue produced both Wh and yes/no questions.

We also performed a further analysis considering the longitudinal data of two more children who were recorded bi-weekly. Here we could assess, for each child, when yes/no questions first appeared relative to the other structures. The longitudinal data yielded similar results, as shown in Tables 3 and 4 (to be discussed in detail in Section 4.4): for both children, when they were at Stage 1 they produced no questions, and then at Stage 2 they produced both Wh and yes/no questions, both appearing within two weeks, with no structures that belong to Stage 3 yet.

An additional indication for the close proximity between the appearance patterns of the two types of questions can be seen when analyzing the time of first appearance of each question type in the longitudinal data of nine children (see Appendix A). These data indicate that 3 children produced a Wh question before a yes/no question, 3 had them simultaneously, and 3 started using yes/no questions before Wh questions, all within 6 weeks.

Taken together, the 56 children's speech samples as well as the longitudinal data indicate that yes/no questions are acquired together with Wh questions in Stage 2, both appear later than Stage 1, where children produce declarative SV sentences, and before Stage 3 where they produce embedded questions (and embedded declaratives, relatives, and topicalization)

The finding that yes/no questions appeared simultaneously with root Wh questions supports the possibility according to which the yes/no feature resides in $\mathrm{Q}$, in the lower LP layer. One 
possible implementation would be to assume, following much literature, that a null yes/no operator is present in polar questions, the null counterpart of the overt Wh operator in Wh questions. This null operator would reside in the specifier position of the $\mathrm{Q}$ head, in the lower part of the LP. Once this position becomes available, it may attract a Wh operator, or host a yes/no operator.

\begin{tabular}{|c|c|c|c|c|c|c|}
\hline STAGE & $\begin{array}{c}\text { Age } \\
\text { (months) }\end{array}$ & Root WH & Root $\mathrm{Y} / \mathrm{N}$ & $\begin{array}{c}\text { Embedded } \\
\text { WH }\end{array}$ & $\begin{array}{c}\text { Embedded } \\
\mathrm{Y} / \mathrm{N}\end{array}$ & $\begin{array}{l}\text { Embedded } \\
\text { declarative }\end{array}$ \\
\hline 2 & 18 & $\checkmark$ & $\checkmark$ & 0 & 0 & 0 \\
\hline 2 & 20 & $\checkmark$ & $\checkmark$ & 0 & 0 & 0 \\
\hline 1 & 22 & 0 & & 0 & 0 & 0 \\
\hline 1 & 22 & 0 & & 0 & 0 & 0 \\
\hline 2 & 22 & $\checkmark$ & $\checkmark$ & 0 & 0 & 0 \\
\hline 0 & 23 & 0 & 0 & 0 & 0 & 0 \\
\hline 0 & 23 & 0 & 0 & 0 & 0 & 0 \\
\hline 0 & 23 & 0 & 0 & 0 & 0 & 0 \\
\hline 2 & 23 & $\checkmark$ & $\checkmark$ & 0 & 0 & 0 \\
\hline 2 & 23 & $\checkmark$ & $\checkmark$ & 0 & 0 & 0 \\
\hline 1 & 23 & 0 & 0 & 0 & 0 & 0 \\
\hline 2 & 24 & $\checkmark$ & $\checkmark$ & 0 & 0 & 0 \\
\hline 0 & 24 & 0 & 0 & 0 & 0 & 0 \\
\hline 2 & 24 & $\checkmark$ & & 0 & 0 & 0 \\
\hline 0 & 24 & 0 & 0 & 0 & 0 & 0 \\
\hline 1 & 25 & 0 & & 0 & 0 & 0 \\
\hline 2 & 25 & $\checkmark$ & $\checkmark$ & 0 & 0 & 0 \\
\hline 1 & 26 & 0 & 0 & 0 & 0 & 0 \\
\hline 2 & 26 & $\checkmark$ & $\checkmark$ & 0 & 0 & 0 \\
\hline 2 & 27 & 0 & $\checkmark$ & 0 & 0 & 0 \\
\hline 3 & 29 & 0 & $\checkmark$ & $\checkmark$ & 0 & $\checkmark$ \\
\hline 3 & 30 & $\checkmark$ & $\checkmark$ & $\checkmark$ & 0 & $\checkmark$ \\
\hline 3 & 30 & $\checkmark$ & 0 & 0 & 0 & 0 \\
\hline 3 & 30 & $\checkmark$ & 0 & $\checkmark$ & 0 & 0 \\
\hline 3 & 32 & $\checkmark$ & 0 & 0 & 0 & $\checkmark$ \\
\hline 3 & 33 & $\checkmark$ & $\checkmark$ & $\checkmark$ & 0 & $\checkmark$ \\
\hline 3 & 35 & $\checkmark$ & $\checkmark$ & 0 & 0 & $\checkmark$ \\
\hline 3 & 35 & $\checkmark$ & $\checkmark$ & $\checkmark$ & 0 & 0 \\
\hline 3 & 35 & $\checkmark$ & $\checkmark$ & 0 & $\checkmark$ & 0 \\
\hline 2 & 35 & $\checkmark$ & $\checkmark$ & 0 & 0 & 0 \\
\hline 3 & 36 & $\checkmark$ & $\checkmark$ & $\checkmark$ & 0 & 0 \\
\hline 3 & 36 & $\checkmark$ & $\checkmark$ & 0 & 0 & $\checkmark$ \\
\hline 3 & 37 & $\checkmark$ & $\checkmark$ & 0 & 0 & 0 \\
\hline 3 & 37 & $\checkmark$ & $\checkmark$ & $\checkmark$ & 0 & 0 \\
\hline 2 & 38 & 0 & 0 & 0 & 0 & 0 \\
\hline 3 & 39 & $\checkmark$ & $\checkmark$ & 0 & $\checkmark$ & $\checkmark$ \\
\hline 3 & 39 & $\checkmark$ & 0 & $\checkmark$ & 0 & $\checkmark$ \\
\hline 3 & 39 & $\checkmark$ & $\checkmark$ & $\checkmark$ & 0 & 0 \\
\hline 3 & 41 & $\checkmark$ & $\checkmark$ & $\checkmark$ & 0 & 0 \\
\hline 3 & 43 & $\checkmark$ & $\checkmark$ & $\checkmark$ & 0 & $\checkmark$ \\
\hline 3 & 48 & $\checkmark$ & $\checkmark$ & $\checkmark$ & 0 & $\checkmark$ \\
\hline 3 & 51 & $\checkmark$ & $\checkmark$ & $\checkmark$ & 0 & $\checkmark$ \\
\hline 3 & 53 & $\checkmark$ & $\checkmark$ & $\checkmark$ & 0 & $\checkmark$ \\
\hline 3 & 57 & $\checkmark$ & $\checkmark$ & 0 & 0 & $\checkmark$ \\
\hline 3 & 58 & 0 & 0 & 0 & 0 & $\checkmark$ \\
\hline 3 & 58 & $\checkmark$ & $\checkmark$ & $\checkmark$ & 0 & $\checkmark$ \\
\hline 3 & 59 & $\checkmark$ & $\checkmark$ & $\checkmark$ & 0 & $\checkmark$ \\
\hline 3 & 61 & $\checkmark$ & $\checkmark$ & $\checkmark$ & $\checkmark$ & $\checkmark$ \\
\hline 3 & 62 & $\checkmark$ & $\checkmark$ & $\checkmark$ & 0 & $\checkmark$ \\
\hline 3 & 63 & $\checkmark$ & $\checkmark$ & $\checkmark$ & 0 & $\checkmark$ \\
\hline 3 & 64 & $\checkmark$ & $\checkmark$ & $\checkmark$ & 0 & $\checkmark$ \\
\hline 3 & 67 & $\checkmark$ & $\checkmark$ & $\checkmark$ & 0 & $\checkmark$ \\
\hline 3 & 68 & $\checkmark$ & 0 & $\checkmark$ & 0 & $\checkmark$ \\
\hline 3 & 68 & $\checkmark$ & $\checkmark$ & $\checkmark$ & 0 & $\checkmark$ \\
\hline 3 & 70 & $\checkmark$ & $\checkmark$ & $\checkmark$ & $\checkmark$ & $\checkmark$ \\
\hline 3 & 73 & $\checkmark$ & $\checkmark$ & $\checkmark$ & 0 & $\checkmark$ \\
\hline
\end{tabular}

Friedmann et al.

Glossa: a journal of

general linguistics

DOI: $10.16995 /$ glossa.5877

Table 2 The pattern of acquisition of root and embedded Wh and $\mathrm{Y} / \mathrm{N}$ questions. 


\subsection{Stage 3. The higher field of the LP}

In the next stage, Stage 3, the higher field of the left periphery becomes available (see Figure 6). This allows for the appearance of relative clauses and topicalization structures, together with sentence embedding. As summarized in Table 1, in line with the Guttman Scale implicational logic, all children who were at Stage 3 and produced any of Stage 3 structures (relative clauses, topicalization, sentential embedding) also produced some structures that belong to Stage 2 (root Wh/yes no questions and Adverbs in Mod), and SV sentences, which belong to Stage 1 . The same Guttman scale could be seen also in the repetition task: all children who could repeat correctly the relative clauses and the topicalization sentences could also repeat the SV sentences (with unaccusative and unergative/transitive verbs).

It is not surprising that relative clauses appear together with sentential embedding, because relative clauses are embedded clauses. A more surprising property of the natural production data of this stage is the finding that the appearance of root topicalization structures coincides with

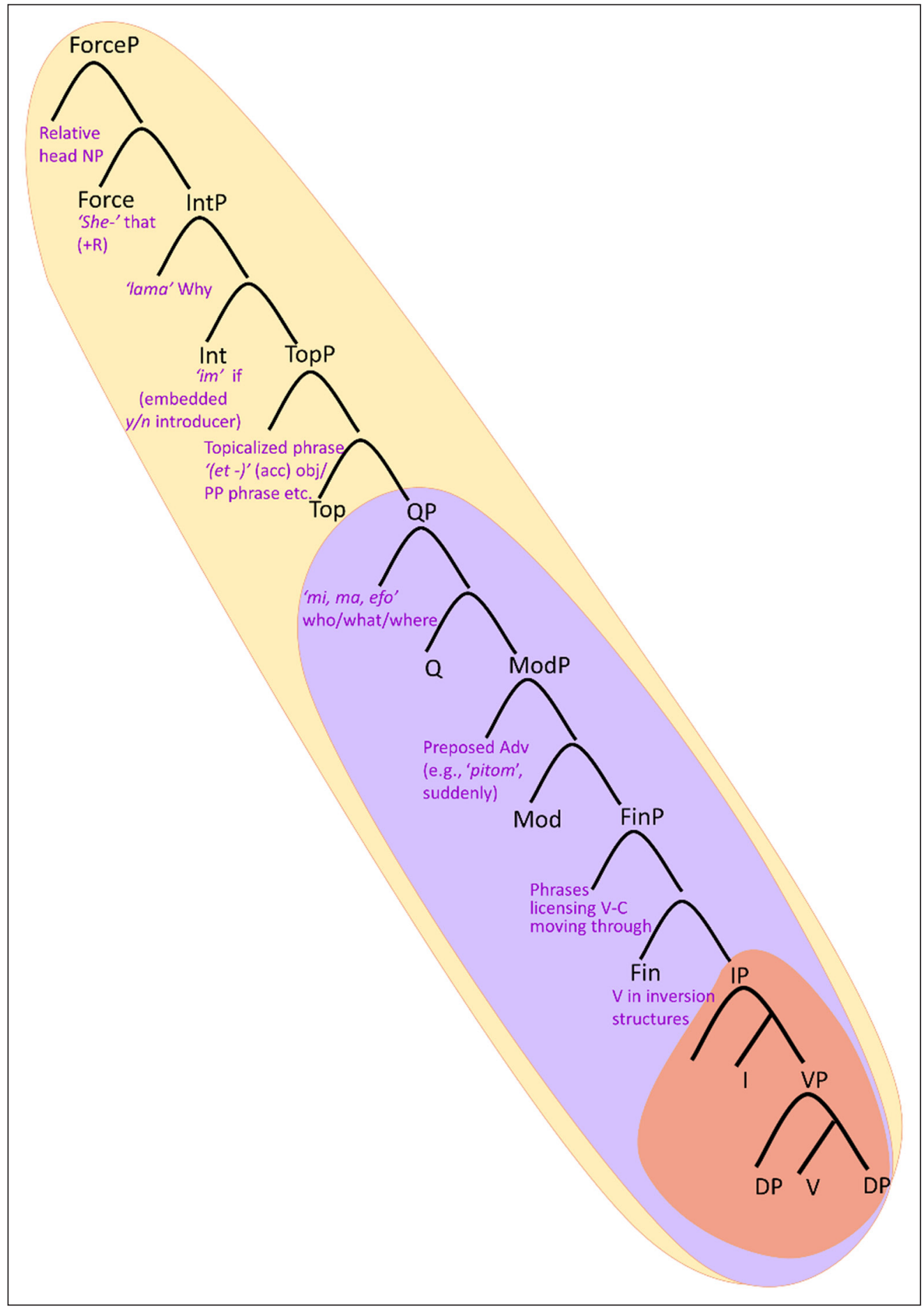


the appearance of embedded clauses, as topicalization is a typical main clause phenomenon, much as root question formation. We suggest that the co-occurrence of the three constructions is a straightforward consequence of the fact that they all involve positions in the same left peripheral area, constituting the higher field of the LP.

\subsubsection{Embedded declaratives, embedded questions, and the selection of clauses}

Let us concentrate now on embedding, starting from the most straightforward case, the embedding of selected declarative clauses. A natural assumption about selection is that the selection of finite embedded clauses is categorially uniform, with the selected property expressed in the highest position of the complementizer system. Namely, all verbs selecting a finite complement select a ForceP, in which the selection properties of different verbs are expressed: say selects + declarative, wonder selects + interrogative, surprise may select + exclamative. This follows from the classical theory of selection in which selection is satisfied under sisterhood (Chomsky 1965). In minimalist terms, this amounts to saying that external Merge only sees the labels of the categories that undergo Merge and cannot penetrate lower positions, internal to the structure being merged. Therefore, selection does not work through Agree-like relations, which could take place at a distance. In sum, selection (of finite clauses) ${ }^{15}$ requires the projection of the whole structure up to the Force layer.

Embedded declaratives in Hebrew are introduced by the embedding marker she-, which expresses both declarative force and finiteness. We assume that she-is in Force, satisfying the selectional properties of the matrix verb. This relation between force and finiteness could be expressed through an Agree relation between Force and Fin.

As for (finite) relative clauses, they are also introduced in Hebrew by the complementizer she, much like Romance che and que, English that (see Kayne 1976, for the classical analysis of the introducer of the relative clause as a complementizer). So, the natural assumption, along the lines of Rizzi (1997), based on Romance distributional evidence, is that the complementizer introducing relative clauses also occurs in the highest position of the CP system, in Force, as illustrated in the Hebrew cartographic description in Section 1.1 above (Figure 1).

Figure 7 spells out our basic assumptions with respect to relative clauses. As for the position of the nominal head of the relative clause, we adopt a raising analysis, along the lines of Bianchi (1999) developing Kayne (1994), with D externally merged higher than ForceP. The relative NP moves to the specifier of Force. The Force head of a relative clause is endowed with $a+R$ feature, the criterial feature attracting movement of NP into its specifier. ${ }^{16}$

The discussion of selection anchored in Force also directly pertains to embedded questions, which are selected clauses as well. Under the general theory of selection that we are assuming, the selection of embedded questions will also occur in Force. This would mean that in Force there is a question feature. Many languages provide evidence that the Wh element or the embedded yes/no question marker in fact occur in a position lower than the embedded Force head (Puskás 2000; Rizzi 2013a). So, we follow the analysis in Rizzi (2013b) and assume an Agree relation between the embedded Force (selected by a higher verb) and Q (for embedded Wh questions), or Int (for embedded yes/no questions). The essential point is that under the simple and general view of selection, embedded questions will be accessible to the child at a stage in which the whole CP structure is available, including the highest layer that contains Force. This predicts that embedded Wh questions and embedded yes/no questions would appear together with embedded declarative sentences, all selected by a higher selector - a 


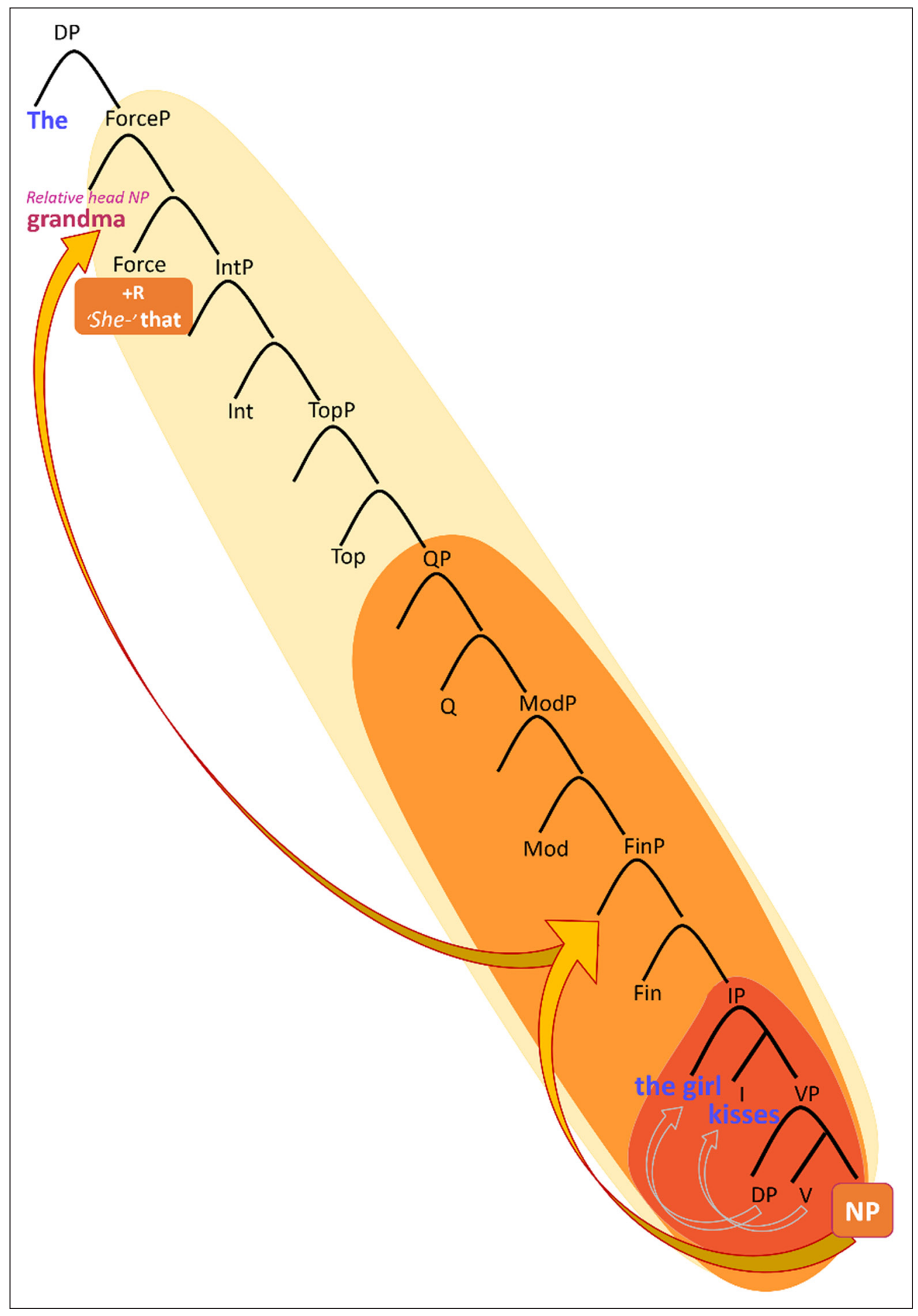

higher verb in the case of declaratives and questions (and plausibly the determiner in the case of relative clauses). And indeed, this is the picture emerging from natural speech, as shown in Table 2: embedded Wh questions appear exactly at the same time as embedded declaratives, in Stage $3 .{ }^{17}$ Embedded whether/if questions also appear in this stage, with the usual individual age variation (e.g., one girl produced yes/no questions already at 19 months, and another at 35 months).
Figure 7 The cartographic structure of relative clauses in Hebrew.

17 The acquisition of embedded questions later than root ones is consistent also with J. de Villiers' (1991) findings for English, that root argument Wh questions are acquired before embedded Wh questions (and why questions). De Villiers suggested an analysis of this finding according to which root argument Wh questions are produced at a stage in which CP is not yet available (so Wh questions are adjoined to IP), and embedded Wh questions and why questions are acquired later, when CP is present. At that point, root argument questions would be reanalyzed as targeting CP. De Villiers' analysis is similar to ours in suggesting structural stages that involve the availability of larger and larger chunks of the tree. Our proposal differs from hers in that it simply capitalizes on positional differences in the cartographic representation, and does not require reanalysis of earlier stages when later stages are reached. 
It is crucial to notice that Stage 3 is not only an "embedding stage". We have already mentioned that root topicalization structures appear in Stage 3. This follows from the cartography of the CP system, in which positions hosting topics cross-linguistically appear in the higher field (see our cartographic Section 1.1 above demonstrating this order for Hebrew). ${ }^{18}$ In the next section we show that another non-embedded construction, root why questions, also appears in Stage 3.

\subsubsection{From the Growing Trees approach to new data on acquisition}

4.3.2.1 Why questions

A look at the map in Figure 1 highlights another non-embedded construction that crucially involves a position in the higher field of the LP, and hence is predicted to appear at Stage 3: Why questions. The Wh element why has been shown to occur in a position distinct from, and higher than the Spec/Q position hosting other Wh elements (Rizzi 2001). We have shown in example (9) above, ${ }^{19}$ that this is the case in Hebrew as well: lama (why) appears above TopP, like the embedded yes/no marker im (if). This is similar to Italian, where perché (why), like the embedded yes/no marker se (if), can precede a topic (in main and embedded clauses). This observation supports the hypothesis that lama (and perché) and im (and se) occupy the layer Int, higher than the landing site of other Wh elements, Spec/Q (see Thornton 2008 for supporting developmental data from the acquisition of English, and Thornton 2016 for a discussion of the late acquisition of why questions; see various contributions in Soare, 2021, for cross-linguistic evidence supporting the special position of why). If why questions crucially involve Int, which is in the higher LP field, we predict why questions to appear only in Stage 3, when the Int position becomes available (see Figure 6).

This theoretical prediction led us to analyze the different types of questions in the children's production, and to examine when why questions appear relative to the other types of Wh questions, and in which stage of acquisition the children who already produce them are.

The acquisition data, summarized in Table 1, clearly show that why questions are indeed acquired only at Stage 3. The production of why questions perfectly matched the acquisition of other structures that appear in Stage 3: CP embedding, topicalization, and relative clauses, and does not appear for children who produce Wh questions but do not yet show evidence for the acquisition of Stage 3.

There were 17 children who produced why questions, all of them were at Stage 3, as indicated by their production of CP embedding with she- (all of them produced embedded sentences, and all but two also produced relative clauses or topicalization structures). None of the children who were at Stage 2 or 1 produced any why questions.

It is worth noticing that the cartographic analysis predicts a split between why and all other (root) Wh elements, rather than a split between argument and adjunct questions because

18 The finding that topics are acquired later than (root) Wh questions converges with Tsimpli's (2005) observation that topic structures in clitic left dislocation (CLLD) in Greek are acquired later than Focus/Wh. In our system, this distinction follows from the positional properties in the cartographic map and does not rely on feature interpretability. Indeed, Topic features must be visible at LF for interpretation as much as Focus/Q features are. Additionally, topicalization in Hebrew does not include clitic resumption, so the developmental sequence cannot be attributed to the presence of the clitic resuming the dislocated topics.

19 Another type of evidence for why appearing above other Wh elements in Hebrew comes from colloquial Hebrew expressions that include both why and who/what in that order which, accompanied with the relevant hand gesture (open hand turning face-up), roughly, mean "why on earth should I do that?" or "this is a complete exaggeration".

(i) Lama ma kara?

why what happened?

(ii) Lama ma?

why what?

(iii) Lama mi met?

why who died?

In these examples (i-iii) there is no audible pause between lama and $m a / m i$, suggesting that we do not have two separate clauses here (Doron \& Wolf 2016; Khalaily \& Doron 2016). 
adjunct Wh elements other than why target the same spec-Q position as do argument Wh elements. The split why vs. all other Wh elements is supported by the acquisition data, with why questions acquired after all other Wh questions (argument and adjunct). The acquisition data indicates that where questions are abundant, from the very early questions the children produced; the children also produced, with lower frequency, how, when, and where-to questions. It is worth noting that why questions occur very frequently in the corpus once Stage 3 is achieved (17 of the 34 children in Stage 3 produced why questions), and once acquired they appear very frequently in each corpus (for example, Leor, one of the children who were recorded longitudinally, produced in a single recording at age 2;11 64 why questions). So, the late acquisition of why questions is not a function of its rarity in the children's production but rather it is tightly related to the position of why in the LP. We also see that there is no slow increase in the use of why questions with age but rather a sudden appearance corresponding to the acquisition of Stage 3. (Anecdotally, parents often talk about "the why period", which starts abruptly and opens up a stretch of many why questions).

The late acquisition of why questions (and of embedding) immediately refutes an alternative account according to which constructions that involve movement are acquired later than structures without movement because structures with movement are harder. Why questions, unlike other argument and adjunct Wh questions, presumably do not involve movement (Rizzi 2001). ${ }^{20}$ Had the movement structures been acquired later than no-movement ones, we would have expected why questions to be acquired before, rather than after, other Wh questions. The data, however, shows the exact opposite order, with why questions being the last to appear. Similarly, clausal embedding does not involve movement, still, it appears in Stage 3, after Wh questions, which do involve movement (See Hamann \& Tuller 2014, for embedding as a factor of complexity).

\subsubsection{Adverb preposing and topicalization}

We can now examine the data with respect to the relation between two types of preposing: adverb preposing and topicalization. In the cartographic section (Section 1.1) we saw that adverb preposing targets a dedicated position Mod, distinct from and lower than Top, which is targeted by preposed topics.

Given that Mod is lower than Q and given our stage typology, we expect Mod to be available in Stage 2 alongside Wh questions, whereas topicalization is only expected to be available in Stage 3. And indeed, the acquisition data manifest this distinction clearly: there were five children (of the 12 children in Stage 2) who produced preposed adverbs ${ }^{21}$ but still no structure related to Stage 3, in particular no topicalization structure. Conversely, no child produced topicalization structures without structures relating to Stage 2 (see Table 1).

The emerging picture of the three stages in structure acquisition is summarized in Figure $8 .^{22}$

20 See Shlonsky \& Soare (2011) for the assumption of a local movement in CP in why questions; in any event, no movement from clause-internal position is assumed in either approach.

21 Most adverbs the children produced at this stage were "now" and "suddenly". There were also some presentational structures beginning with "hine", which roughly corresponds to "here is" in English, or Italian presentational "ecco". For this calculation we analysed hine as an adverb in Mod. We base this analysis on the availability of sentences in which hine precedes the subject (i), and on Zanuttini's (2017) analysis of ecco.

(i) Hine safta ba'a (Leor 2;2)

here grandma comes

'Here comes grandma.'

Even if hine turns out not to be analyzable along these lines, the results would change only minimally and for one child (there would be 4, not 5, children manifesting Mod in Stage 2).

22 One may wonder what the children who were not yet in Stage 1 were producing. The five children in the corpus who have not yet produced SV sentences, and the two children in the longitudinal data before they produced SV sentences either produced single words (which may correspond to a pre-Merge stage of only lexical terminals), or produced in addition to single words also structures of the form want + object or imperative + object, which may correspond to a single merge stage. In the current paper we do not address the analysis of the children in these very early phases of the development of syntax. 


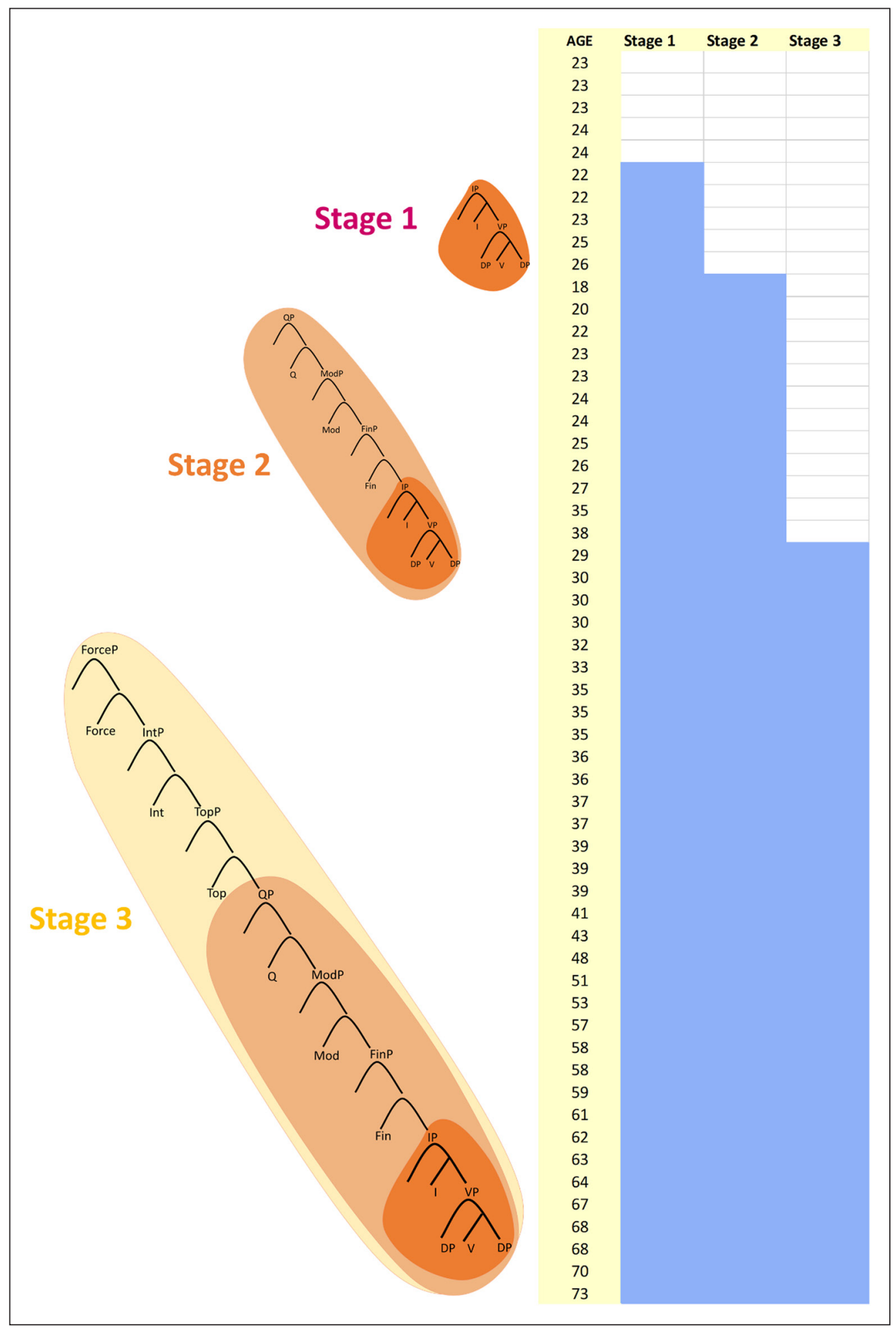

\subsection{Longitudinal data: The same stages of acquisition}

The results summarized in Figure 8 were obtained through a look at different children and the structures each of them was already able to produce. This yielded the three stages of acquisition. Another way to examine stages of acquisition is to observe the order of acquisition of various structures within the same child, and examine which structure precedes which structure, and which structures appear at the same time. We examine here whether the stages observed in the group of 56 children, also with respect to the three new structures we examined in this section, were also observable at the longitudinal data within a child by analyzing the longitudinal data of the two most densely tested children reported in Friedmann \& Reznick (this volume).

Method. We examined the acquisition of the various structures in the production of Hagar and Leor. Hagar was recorded 114 times between the ages of $1 ; 7-2 ; 11$, with an average of 219 utterances per sample. Leor was recorded 79 times between 1;9-3;0, with an average of 297 utterances per sample. The total number of utterances analysed for these two children was
Figure 8 The different stages as reflected in the corpus: Stage 1 in the table includes SV structures with unergatives and unaccusatives, SV and VS structures with unaccusatives; Stage 2 includes root Wh and yes/no questions and preposed adverbs; Stage 3 includes relative clauses, topicalization, why questions, and embedded declaratives and questions. (Blue cells in the table indicate that a structure belonging to this stage has been produced; ages reported in months). 
16,002. Their data are collapsed to one-month periods. For each of the children we examine when each of the structures appeared first in their spontaneous speech.

Results. The structures we examined were acquired at exactly the same order, creating the same stages of growing trees as identified in the group analysis.

The order of acquisition, summarized for Hagar in Table 3 and for Leor in Table 4, included a Stage 1 in which SV structures appeared (Hagar did not produce unaccusative verbs in Stage 1), and then Stage 2 with root Wh questions and yes/no questions, and then Stage 3 with relative clauses, topicalization structures, why questions and sentential embedding. Namely, the sample analysis was completely confirmed by the longitudinal analysis.

\begin{tabular}{|c|c|c|c|c|c|c|c|c|c|}
\hline \multirow{2}{*}{$\begin{array}{l}\text { HAGAR } \\
\text { AGE }\end{array}$} & \multicolumn{3}{|c|}{ STAGE 1} & \multicolumn{2}{|c|}{ STAGE 2} & \multicolumn{4}{|c|}{ STAGE 3} \\
\hline & $\begin{array}{l}\text { SV } \\
\text { simple }\end{array}$ & $\begin{array}{l}\text { SV } \\
\text { unacc }\end{array}$ & $\begin{array}{l}\text { VS } \\
\text { unacc }\end{array}$ & WH & $Y / n$ & Why & Relative & $\begin{array}{c}\text { Topicalizati } \\
\text { on }\end{array}$ & Embedding \\
\hline $19-19.5$ & $\checkmark$ & & & 0 & 0 & 0 & 0 & 0 & 0 \\
\hline 20 & $\checkmark$ & $\checkmark$ & $\checkmark$ & $\checkmark$ & $\checkmark$ & 0 & 0 & 0 & 0 \\
\hline 21 & $\checkmark$ & $\checkmark$ & $\checkmark$ & 0 & $\checkmark$ & 0 & 0 & 0 & 0 \\
\hline 22 & $\checkmark$ & $\checkmark$ & 0 & $\checkmark$ & $\checkmark$ & 0 & 0 & 0 & 0 \\
\hline 23 & $\checkmark$ & $\checkmark$ & $\checkmark$ & $\checkmark$ & $\checkmark$ & 0 & 0 & 0 & $\checkmark$ \\
\hline 24 & $\checkmark$ & $\checkmark$ & 0 & $\checkmark$ & $\checkmark$ & $\checkmark$ & 0 & 0 & $\checkmark$ \\
\hline 25 & $\checkmark$ & $\checkmark$ & $\checkmark$ & $\checkmark$ & $\checkmark$ & 0 & $\checkmark$ & $\checkmark$ & 0 \\
\hline 26 & $\checkmark$ & $\checkmark$ & 0 & $\checkmark$ & $\checkmark$ & $\checkmark$ & 0 & $\checkmark$ & $\checkmark$ \\
\hline 27 & $\checkmark$ & $\checkmark$ & $\checkmark$ & $\checkmark$ & $\checkmark$ & 0 & $\checkmark$ & $\checkmark$ & $\checkmark$ \\
\hline 28 & $\checkmark$ & $\checkmark$ & $\checkmark$ & $\checkmark$ & $\checkmark$ & $\checkmark$ & 0 & $\checkmark$ & $\checkmark$ \\
\hline 29 & $\checkmark$ & $\checkmark$ & 0 & 0 & $\checkmark$ & 0 & $\checkmark$ & $\checkmark$ & $\checkmark$ \\
\hline 30 & $\checkmark$ & $\checkmark$ & $\checkmark$ & $\checkmark$ & $\checkmark$ & $\checkmark$ & $\checkmark$ & $\checkmark$ & $\checkmark$ \\
\hline 31 & $\checkmark$ & $\checkmark$ & $\checkmark$ & $\checkmark$ & $\checkmark$ & 0 & $\checkmark$ & $\checkmark$ & $\checkmark$ \\
\hline 32 & $\checkmark$ & $\checkmark$ & $\checkmark$ & $\checkmark$ & $\checkmark$ & $\checkmark$ & $\checkmark$ & 0 & $\checkmark$ \\
\hline 33 & $\checkmark$ & $\checkmark$ & 0 & $\checkmark$ & $\checkmark$ & $\checkmark$ & $\checkmark$ & $\checkmark$ & $\checkmark$ \\
\hline $34-35$ & $\checkmark$ & $\checkmark$ & $\checkmark$ & $\checkmark$ & $\checkmark$ & $\checkmark$ & 0 & 0 & $\checkmark$ \\
\hline
\end{tabular}

\begin{tabular}{|c|c|c|c|c|c|c|c|c|c|c|}
\hline \multirow{2}{*}{$\begin{array}{l}\text { LEOR } \\
\text { AGE }\end{array}$} & \multicolumn{3}{|c|}{ STAGE 1} & \multicolumn{2}{|c|}{ STAGE 2} & \multicolumn{5}{|c|}{ STAGE 3} \\
\hline & $\begin{array}{l}\text { SV } \\
\text { simple }\end{array}$ & $\begin{array}{l}\text { SV } \\
\text { unacc }\end{array}$ & $\begin{array}{l}\text { VS } \\
\text { unacc }\end{array}$ & WH & $y / n$ & why & relative & $\begin{array}{l}\text { topicali } \\
\text { zation }\end{array}$ & $\begin{array}{l}\text { embedd } \\
\text { ing decl }\end{array}$ & $\begin{array}{c}\text { embedded } \\
\text { questions }\end{array}$ \\
\hline $21-21.5$ & $\checkmark$ & 0 & $\checkmark$ & 0 & 0 & 0 & 0 & 0 & 0 & 0 \\
\hline $22-22.5$ & $\checkmark$ & 0 & 0 & 0 & 0 & 0 & 0 & 0 & 0 & 0 \\
\hline $23-23.5$ & $\checkmark$ & $\checkmark$ & $\checkmark$ & $\checkmark$ & $\checkmark$ & 0 & 0 & 0 & 0 & 0 \\
\hline $24-24.5$ & $\checkmark$ & $\checkmark$ & $\checkmark$ & $\checkmark$ & $\checkmark$ & 0 & 0 & 0 & 0 & 0 \\
\hline $25.5-26$ & $\checkmark$ & $\checkmark$ & $\checkmark$ & $\checkmark$ & $\checkmark$ & 0 & $\checkmark$ & $\checkmark$ & 0 & $\checkmark$ \\
\hline $26-26.5$ & $\checkmark$ & $\checkmark$ & $\checkmark$ & $\checkmark$ & $\checkmark$ & $\checkmark$ & $\checkmark$ & $\checkmark$ & 0 & $\checkmark$ \\
\hline $27-27.5$ & $\checkmark$ & $\checkmark$ & $\checkmark$ & $\checkmark$ & $\checkmark$ & 0 & 0 & $\checkmark$ & $\checkmark$ & 0 \\
\hline $28-28.5$ & $\checkmark$ & $\checkmark$ & $\checkmark$ & $\checkmark$ & $\checkmark$ & 0 & $\checkmark$ & $\checkmark$ & $\checkmark$ & $\checkmark$ \\
\hline $29-29.5$ & $\checkmark$ & $\checkmark$ & $\checkmark$ & $\checkmark$ & $\checkmark$ & 0 & 0 & $\checkmark$ & $\checkmark$ & $\checkmark$ \\
\hline $30-30.5$ & $\checkmark$ & $\checkmark$ & $\checkmark$ & $\checkmark$ & $\checkmark$ & 0 & $\checkmark$ & 0 & 0 & $\checkmark$ \\
\hline $31-31.5$ & $\checkmark$ & $\checkmark$ & $\checkmark$ & $\checkmark$ & $\checkmark$ & 0 & $\checkmark$ & $\checkmark$ & $\checkmark$ & $\checkmark$ \\
\hline $32-32.5$ & $\checkmark$ & $\checkmark$ & $\checkmark$ & $\checkmark$ & $\checkmark$ & 0 & 0 & $\checkmark$ & $\checkmark$ & $\checkmark$ \\
\hline $33-33.5$ & $\checkmark$ & $\checkmark$ & $\checkmark$ & $\checkmark$ & $\checkmark$ & 0 & $\checkmark$ & $\checkmark$ & $\checkmark$ & $\checkmark$ \\
\hline $34-34.5$ & $\checkmark$ & $\checkmark$ & $\checkmark$ & $\checkmark$ & $\checkmark$ & $\checkmark$ & $\checkmark$ & $\checkmark$ & $\checkmark$ & $\checkmark$ \\
\hline $35-35.5$ & $\checkmark$ & $\checkmark$ & $\checkmark$ & $\checkmark$ & $\checkmark$ & $\checkmark$ & $\checkmark$ & $\checkmark$ & $\checkmark$ & $\checkmark$ \\
\hline $36-36.5$ & $\checkmark$ & $\checkmark$ & $\checkmark$ & $\checkmark$ & $\checkmark$ & $\checkmark$ & $\checkmark$ & $\checkmark$ & $\checkmark$ & $\checkmark$ \\
\hline
\end{tabular}

\subsection{Not only structure: Intervention locality}

A considerable body of experimental work shows that in many languages, including Hebrew, children cannot understand and produce certain object relative clauses, object topicalization structures, and object Wh questions before age 6 (Correa 1982; 1995; de Vincenzi 1991; de Villiers et al. 1994; McKee et al. 1998; Stavrakaki 2001; Friedmann \& Novogrodsky 2004; Friedmann et al. 2009; Belletti \& Contemori 2010; Friedmann \& Costa 2010; Costa et al. 2014; Belletti et al. 2012; Biran \& Ruigendijk 2015; Bentea 2016). The results that emerged from the spontaneous speech samples seem prima facie to contradict these earlier findings, in two
Friedmann et al.

Table 3 A growing tree: Longitudinal data - Hagar.

Table 4 A growing tree: Longitudinal data - Leor. 
important ways. Firstly, these three structures appear early in our samples, with some children producing object questions as early as one year and a half, and some producing object relatives and topicalization structures around age two and a half. Secondly, whereas previous work consistently found subject-object asymmetries, with object dependencies significantly harder to understand and produce than subject ones, the natural data samples showed that subject- and object relatives appear together, and so do subject- and object questions.

How can these seemingly contradicting data be reconciled? We propose that, in fact, there is no contradiction here, but rather a new piece added to the puzzle. In earlier work (Friedmann, et al. 2009), we proposed that the difficulty in the comprehension and production of object A-bar dependencies cannot be characterized as a problem with the A-bar movement or a problem with the object dependency per se but rather the problem resides in intervention locality considerations: the difficulty arises in configurations in which a lexically-restricted (object) DP moves across another lexically-restricted (subject) DP, an intervention configuration problematic for children, a difficulty captured by the featural Relativized Minimality approach (Friedmann et al. 2009; building on Rizzi 1990; 2004; Starke 2001).

And indeed, a further analysis of the spontaneous speech samples points exactly in this direction: the children produced many A-bar structures, including subject and object relatives, topicalizations, and Wh questions, and from age 3;3 all of them did, but none of the relatives, topicalizations, and Wh questions in the samples included an intervention structure of the relevant type, with a lexically-restricted DP crossing another one.

Instead, all the object dependencies that the children produced were structures without intervention. The object relatives they produced included a pronominal intervening subject, in the form of an arbitrary plural null subject (example (17)), or a referential (null/overt) subject pronoun (examples (18) and (19) respectively). Children also produced free object relatives at this stage (9 of the 14 children who produced object relatives).

Object relative with arbitrary pro subject: Ze oxel she-(arb pro)-notnim b-a-tei. this food that- give.PL in-the-tea 'that's food that one puts(?) in the tea.'

Object relative with null pro subject:

Hine ha- gorila she-(pro)-macat. here the-gorilla that- found.2SG.FEM 'Here is the gorilla that you found.'

$$
\begin{array}{ll}
\text { Object relative with pronoun subject: } & \text { Ani ekax od cura she-ani roce. } \\
\text { I take.FUT another form that-I want } \\
\text { 'I will take another form that I want.' }
\end{array}
$$

For Wh questions, intervention occurs when the Wh element is of the which type, and hence, lexically-restricted, and the subject is also lexically-restricted. The object questions that appeared in the samples were mostly who/what questions, and the few which object questions included a pronominal (null or overt) subject (example 20) (many other utterances included which, but in a simple which-NP structure, like "which orange?").

$$
\begin{aligned}
& \text { Eize tinok (arb pro)-nasim po levad? } \\
& \text { which baby put.FUT.PL here alone } \\
& \text { 'Which baby shall we put here alone?' }
\end{aligned}
$$

Crucially, none of the sentences with object dependencies that the participants produced included a lexically-restricted DP crossing another lexically-restricted DP.

Is it the case that children simply do not use two lexically-restricted noun phrases in the same clause, irrespective of the structure? Well, no. That this is not the case can be shown by the fact that 12 of the 20 children who produced subject relatives did so with a lexically restricted relative head and a lexically restricted object, hence with two lexically restricted DPs but not in an intervention configuration (see example (21). For a similar result in Italian see Martini et al. (2018). 
Subject relatives with two lexically restricted DPs:

Dag be-ceva kesef she- lo maca 1- o xaverim.

fish in-color silver that-no found for-him friends

'A silver-colored fish that hasn't found any friends.'

Is it the case that children avoid lexically-restricted subjects? Again, no, in their simple SV sentences, 45 children produced lexically-restricted subjects.

The fact that we found object relative clauses, object questions, and topicalizations and no subject-object asymmetry is therefore fully consistent both with the Growing Trees approach and with the approach in terms of locality and intervention.

In fact, this points to another dimension of acquisition: acquisition is not just tree structure growing. Rather, we recognize here another developmental stage, which does not have to do with structure building but rather with the development of the ability to compute intervention configurations. The finding that children in our corpus did not spontaneously produce any intervention structure, even though they did produce so many object dependencies, lends strong support in favour of the intervention approach. It also supports the independence of this developmental dimension from structure building: the tree can be grown, and thus be able to host the relevant landing site positions of an A-bar dependency, but on top of it, the child has to be able to compute intervention locality.

\subsection{An open question: Is there a stage earlier than Stage 1?}

Stage 1 of the stages of acquisition of the syntactic tree we presented so far involved a tree consisting of both VP and IP. An open question is whether a stage exists that precedes this Stage 1, that includes an even smaller chunk of the syntactic tree. Three hypothetically possible stages preceding Stage 1 are imaginable. Below we describe each of them and address their hypothetical defining properties. ${ }^{23}$

a) A pre-functional stage of bare VP without IP. One option for a pre-Stage 1 stage would be one in which only a bare VP is available, without the IP layer. Such a "pre-functional" stage, with no functional structure (as in Radford 1990; 1992; 1996), would allow the child to produce SV(O) sentences for transitives and unergatives. Predicting whether or not the child would be able to produce SV for unaccusatives would depend on the assumptions one holds with respect to the derivation of SV with unaccusatives: if the internal argument first moves to the edge of VP and then continues to spec IP, SV with unaccusatives would be possible as well. If, in contrast, movement from the internal argument position targets the spec IP directly, then presumably only the VS order would be available at this early stage for unaccusatives (possibly, with observable definiteness effects, given the early sensitivity to such effects: Belletti \& Bianchi 2016; Belletti 2017). ${ }^{24}$ More straightforwardly, the hypothetical non-availability of the functional structure of the clause will also have implications for inflection: under the assumption that inflectional specifications such as, in particular, agreement with the subject in Phi features, and also tense inflection on the verb, require licensing of the inflected verb by the appropriate head(s) in the inflectional field, in a hypothetical stage without functional structure, the verb would not be properly inflected.

b) A stage of only lower functional layers above VP. Another option for an early stage preceding our Stage 1 is a stage in which VP is available, together with only lower functional layers (e.g., aspect but not tense in the Cinque 1999, hierarchy), but not including higher IP layers up to the position typically occupied by pre-verbal subjects in the adult system (i.e., Spec SubjP, as in Cardinaletti 2004; Rizzi 2006; Rizzi \& Shlonsky 2007). In such a hypothetical stage, the verb would be only partially inflected (e.g., for Aspect, but not for Tense or Agreement. See Antinucci \& Miller 1976; Salustri et al. 2004; see also Tsimpli 2005, for findings regarding Asp acquired before Tense).

23 If there is a one-word stage, which would correspond to a "terminal-only" stage, which does not include presyntactic devices (Bottari et al. 1993), this could be a pre-functional stage. However, once pre-syntactic devices are present, a pre-functional stage becomes unlikely.

24 To simplify the issues, here we have stated this hypothesis in terms of VP structures; if v-VP structures are systematically assumed, the options ramify further. 
See Armon-Lotem 1997; 2008a where such an approach was developed in detail for the acquisition of Hebrew. Similar considerations as in a) above would apply for whether the child would be able to produce SV with unaccusatives.

c) A stage of structure without movement? A different type of possibility for a stage preceding our Stage 1 might be that the structure (VP + IP) is available but movement is not available yet. Internal and external Merge differ in the need of a preliminary search operation, which is only required in internal Merge. A hypothetically possible situation, then, would be that at an early stage, Merge is acquired but Search is not acquired yet. In this situation, structure building (external merge) will be available but movement (internal merge) will not. There could be a stage, then, in which children already have SVO for transitives, SV for unergatives, as these require structure building but no (explicitly visible) movement, but presumably only VS for unaccusatives, as SV with unaccusatives requires movement from the internal argument position to a higher spec position (with a result similar to a) and b) above). The non-availability of movement will also have implications for inflectional specifications on the verb, under the assumption that these are licensed through verb movement. In such a hypothetical stage without movement, the verb would most likely not be properly inflected.

In our data, we have not seen any of these hypothetical stages preceding Stage 1- none of the children showed the patterns expected under any of the three: we did not see a stage in which unaccusatives appeared only in VS order - there were no children who only produced unaccusatives in the VS order, without the SV order, contra possibility c) (and also, under certain assumptions of the movement of the internal argument, contra a) and b)).

Additionally, there is evidence that the agreement system is functioning, even for the children who were in the earliest stage of acquisition in our study, as we did not see children who made (number) agreement errors in SV sentences. ${ }^{25}$ (and see Armon-Lotem \& Berman 2003; ArmonLotem (1997; 2006; 2008b) for an analysis of stages in the acquisition of agreement in early verbs in Hebrew). This means that the functional structure that is responsible for agreement is already in place in their syntactic trees. Under current assumptions, this implies the presence of the relevant functional structure for the checking of agreement and the ability to move there. Another independent indication for the availability of a functional structure at this stage comes from the children's correct production of object case marking. This is evinced in the finding that all 23 children who were at Stage 1 produced the accusative case marker 'et' correctly before the definite object when they repeated simple SVO sentences. (In the samples from natural productions children at Stage 1 produced too few definite objects to allow for analysis of case markers' production).

In conclusion, we did not see in our study any of the hypothetical stages considered in this section for a lower chunk of the tree acquired before Stage 1. This does not necessarily mean they do not exist, as it could be the case that the transition to the next stage is so short that our corpus study could not catch them (Radford 1996). It is fair to conclude, though, that we did not find any evidence supporting them.

\section{Discussion and open issues}

Our research is based on a dialogue between two research domains: the study of the fine details of syntactic structures within the cartographic perspective, and the empirical study of the acquisition of syntax. We have illustrated how this dialogue can be fruitful for both trends of study. Cartography offers a detailed characterization of the hierarchically ordered sets of functional heads that constitute major zones of the clausal structure. Such finely articulated representations can offer a structural basis to understand the stage-by-stage unfolding of

25 In both SV and VS order we have seen some gender agreement errors (10 children produced subject-verb gender agreement errors, not only children who were in Stage 1), which could be a result of the fact that the abstract gender of nouns is a lexical property that needs to be learned noun-by-noun (Biran \& Friedmann 2012), and the abstract gender specification of some of the nouns is not yet fully known to the children (12 children also made noun-adjective gender agreement errors). This contrasts with number agreement errors, which never occurred in SV structures (just in VS structures), which may be related to the fact that number agreement is a reflex of a relation in the functional structure rather than of a lexical property. And this functional structure is already in place. (See the converging conclusion for Italian in Guasti 1993/1994). In VS orders with unaccusative verbs we did see cases of lack of number agreement, which is in line with a very general phenomenon found in many languages, where VS shows optional agreement, whereas SV agreement is obligatory (Guasti \& Rizzi 2002; Meir 2005; Biran \& Friedmann 2012). 
syntactic development. Reciprocally, the study of acquisition can offer new types of evidence to consolidate and refine cartographic results, and also to address questions that are difficult to adjudicate in purely structural terms by just looking at adults' linguistic data.

The fundamental empirical observation on which our analysis is based is that different kinds of structures appear in a strict sequence in the acquisition of Hebrew. This sequence is obscured if one compares age-based groups, due to a large individual variation in the speed of acquisition. But it clearly emerges through the use of Guttman scales, which are particularly effective in revealing implicational relations between properties. The Growing Trees account we propose is based on the empirical results of Friedmann and Reznick (this volume) and on our further explorations of additional structures in the same corpora of 56 children and in the longitudinal data of 9 children. We have built on these results in view of providing a theory-guided analysis also based on new empirical observations.

\subsection{Dialogue: Cartography providing a framework for the description of stages in acquisition}

The cartographic representation of the left periphery offers a natural structural basis to understand the stage-by-stage development of syntactic structures.

The functional structure is ordered according to a sequence of functional heads. The key hypothesis here is that the tree grows in the child's mind in the sense that internal layers are mastered before more external ones, respecting the cartographic hierarchy. Children can produce a certain construction only when they master the relevant functional heads involved in it. As for the acquisition of various types of movement, in a probe-goal approach to movement (internal merge licensed by a probe-goal search operation), the availability of the probing head is essential for a certain type of movement to take place, so the typology of movement reduces (in part) to a structural typology. Therefore, constructions involving functional heads in higher zones and types of movement targeting the higher zones are acquired later depending on the maturational stage of the child.

Stage 1: The first stage we have identified is a stage in which VP + IP are acquired. In this stage, both External and Internal Merge are available but only IP-internal movement is attested (A-movement to subject position, straightforwardly visible with unaccusative verbs). At this stage we also observe agreement licensed by functional structure, and SV structures with unergatives and transitives (and nonfinite complements of verbs, footnote 15). No left peripheral position appears to be active in this stage, and no movements that require these positions.

Stage 2: In the second stage, the lower field of the left periphery has become available. Cartographic analysis shows that the $\mathrm{Q}$ position is in this lower zone (lower than the topic position, the Int position, and the landing site of relative operators). So, Wh movement to the $\mathrm{Q}$ position is acquired, and root questions are found in this stage, as well as root yes/no questions (which presumably involve an operator in Q). The position of Mod, another functional head in the lower LP zone, also becomes available at this stage, allowing for the production of sentences with preposed adverbs. Whereas Wh questions are found in this stage, why questions are not found yet: this follows from the cartographic observation that why is hosted in the Spec of the dedicated left peripheral head, Int, higher than Q (Rizzi 2001). Embedded Wh questions, and full clausal subordination in general, are also not found in the second stage. This follows from the fact that full clausal subordination requires a fully developed C-system, projecting up to Force, the head that expresses the clause type (declarative, interrogative, exclamative, etc., see Cheng 1997; Zanuttini \& Portner 2003) and is selected by higher selectors. Because the selected head, Force, is not available, full clausal subordination is not possible. A-bar constructions such as relative clauses and topicalization are not available yet at this stage, as the higher zone of the left periphery involving their landing sites is not accessible.

Stage 3: In the third stage, the structure of the higher LP becomes available, so that the whole cartographic structure of the C-system becomes accessible to the child. Selection from a higher predicate becomes possible, as the Force head is now available. Therefore, we observe full clausal subordination, so that children at this stage produce embedded declaratives, embedded Wh questions (both subject and object, as well as adjunct questions), and embedded yes/no questions, all selected by a higher predicate. Topicalization becomes available because the Top head is specified in the higher C-zone. Because the relevant landing site for relative clauses in the 
left periphery is now present, subject- and object relative clauses are also acquired in this stage. Why questions also become available, as the crucial head, Int, is specified in the higher CP zone.

Of course, the hierarchical information provided by cartographic analysis can only offer a partial guidance to the sequence of events in development, and interacts with orthogonal factors of complexity. So, for instance, in order to deal with certain intervention configurations in which the moved element and the intervener are both lexically-restricted (such as certain object relatives and certain object which questions), the availability of the structural position of the landing site in the cartographic representation is not enough, and it requires also the capacity to compute certain intervention configurations (the capacity to compute featural inclusion in the system of Friedmann et al. 2009; Belletti et al. 2012). ${ }^{26}$ Therefore, stages in which these capacities are acquired may follow the completion of the acquisition of the syntactic structure, namely, they may follow Stage 3 . When the capacity for computing intervention configurations is acquired, children become able to deal with configurations in which a lexically-restricted DP can be A-bar moved across another lexically-restricted DP. ${ }^{27}$ So, as it should be expected, a comprehensive picture of developmental effects in the acquisition of syntactic constructions can only be provided by a multiplicity of factors, with the structural hierarchy interacting with independent factors of computational complexity. In this paper we have focused on the structural hierarchy, proposing that the structural sequences uncovered by cartographic research can offer a fruitful explanatory key in understanding the developmental sequence of events in the acquisition of syntax.

Due to its grammatical nature, our account predicts that, all things being equal, the same stages documented here on the basis of production data should also hold for comprehension, since grammar is directly implicated in both. It will be interesting yet challenging to test in the future the comprehension of the different structures investigated and see whether they also form a parallel Guttman scale, and whether the stages identified in production co-occur with stages in comprehension.

\subsection{Dialogue: Patterns of acquisition informing syntactic theory regarding tree structure}

Beside conforming to the cartographic order of functional heads, which we discussed above, the pattern of empirical findings emerging from the repetition test and the analysis of children's spontaneous speech suggests novel insights into several theoretical issues concerning the shape of the syntactic tree.

\subsubsection{Zone organization of the functional layers}

We found that the acquisition of the various heads follows strict principles:

a) They are acquired according to their position in the cartographic tree, where higher layers are acquired after lower ones. There is no head-skipping - a higher layer (which in traditional terms would be defined by an X-bar projection of a certain head) cannot be acquired before all lower layers are acquired.

b) Whereas it would be imaginable that children would gradually increase their ability to hold more and more layers, head after head, this is not what we have seen. Our data crucially indicate that the functional heads are acquired in "zones" or "fields", where several hierarchically ordered sets of functional heads are acquired together. This empirical finding supports the view that the left periphery is organized into sub-fields (see Benincà \& Poletto 2004). Similarly to the no-layer skipping, there can also be no zone-skipping - a higher zone cannot be acquired before all lower ones are acquired.

26 Analogously, the delay of passive with respect to A-movement with unaccusatives (in languages in which both are productively present) is plausibly related to a factor independent from the structural hierarchy (possibly the "smuggling" operation required in passive but not with ordinary unaccusatives: see Belletti 2020).

27 Further stages are possible if other observations and considerations are taken into account. For instance, a possible further stage may be identified in which center-embedded relative clauses that is, relative clauses modifying the subject, become available as well. Whereas in Hebrew, for example, final-branching object relatives (in the intervention configuration with two lexically-restricted DPs) are acquired around age 6-7, center embedded relatives (with the relevant intervention configuration) are only mastered around age 10-11 (Friedmann \& Novogrodsky 2004 and references therein). This further stage may also be the stage in which relative clauses in German and Turkish are acquired (Ruigendijk \& Friedmann 2017; Güven \& Friedmann 2019). 
The empirical evidence provided by acquisition identifies different stages, corresponding to different zones. The first to be acquired is the IP zone, then the LP is acquired in two steps, defining two zones: first a lower LP zone including Fin, Mod, and Q and then a higher LP zone that includes Force, Int, and Top.

In addition to providing new evidence for the split of the LP in different fields, our data provide new evidence for the major divide between an inflectional system (IP) and a left-peripheral system: our Stage 1 is characterized by the presence of the IP system, whereas the left peripheral system has not developed yet. Whereas the IP-CP distinction is quite generally assumed, the further distinction between the two LP zones suggests a novel look from acquisition to theoretical discussion: it suggests that each of the two LP zones forms some sort of relatively independent organized unit.

This opens an interesting question of what makes several layers form a zone together, and what dictates the exact point where one zone ends and the next begins. The sub-division of the LP is in fact reminiscent of attempts of identifying distinct LP fields hierarchically organized (such as a topic field vs. a focus field etc., as in e.g., Benincà \& Poletto 2004). We notice, however, that it is not straightforward to identify the property defining the upper zone of the LP as a natural class (e.g., as the "topic field" terminology would suggest) because it includes topics, force markers (embedding markers), and operators such as yes/no operators (in embedded questions), relative clause operators, and why, creatures of very different natures. The relevant generalization distinguishing the higher and lower zones of the LP cannot be expressed by the distinction movement/no movement either, as some of the constructions that become available simultaneously involve movement (topicalization, relativization), and some do not (clausal selection, and plausibly why questions). Nor does the distinction main-subordinate construction provide the right partition: whereas the temporal sequence in the appearance of subordinate questions and relative clauses could evoke such a distinction, it clearly is not sufficient to capture the late appearance of topicalization, which typically occurs in simple main clauses, nor the late occurrence of root why questions. Again the right partition is provided by the cartographic structure, with the Q head appearing in the lower CP field, and Force, Top, and Int occurring in the higher field. Another option, suggested by an anonymous reviewer, is that structures belonging to Stage 2 (lower LP) are purely syntactically-driven whereas those belonging to Stage 3 (higher LP) are discourse-related. This conception correctly captures the fact that topics are found in stage 3 , but does not cut the data pie accurately in other cases. For example, Wh questions are strongly connected to discourse conditions (requests of information from the interlocutor, expected to provide an answer), and yet they appear in the lower LP, whereas relative clauses, less obviously linked to discourse conditions, appear in the higher LP. Moreover, why questions are not more discourse-related than other wh-questions in any obvious sense, and still the two kinds of whelements appear in two different zones. Additionally, sentential complement embedding, which is not obviously related to discourse considerations, is only found in the higher part of LP.

So the search for the basis of the division into zones is still ongoing; among other things, it would also be interesting to see if such a division has a phase correlate, an issue that we leave for future research.

\subsubsection{Main Yes/no questions involving an operator in $\mathrm{Q}$}

A further issue that the acquisition data shed some light on is the way in which main yes/ no questions are expressed in the clausal structure. We showed that the acquisition data can decide between three possibilities for main yes/no questions: an operator in IP, and operator in the lower LP field (in Spec Q), or an operator in the higher LP zone, in Spec-Int. The results, indicating that root yes/no questions are acquired together with root Wh questions pointed to an operator in $\mathrm{Q}$ as the appropriate analysis.

\subsubsection{Support for the position of why}

Our results also directly bear on the special status of why with respect to other Wh elements. The finding that why questions appear in Stage 3, later than other root Wh questions, which appear in Stage 2, and together with other structures residing in the higher zone of the LP, directly supports the view that why occupies a special position in the higher zone of the LP (Rizzi 2001). 


\subsubsection{Support for the distinction between topicalization and adverb preposing}

We have shown that sentences with preposed adverbs and sentences with topicalization start occurring in different stages: adverb preposing in stage 2 , and topicalization in stage 3 . This follows from the different landing sites of the two constructions, respectively in the lower (Mod) and higher (Top) zone of the left periphery. This supports the refined cartographic analysis along the lines of the map in Figure 1: a more traditional analysis assuming IP adjunction for both adverb preposing and topicalization would not provide an adequate structural basis to predict the observed difference.

\subsection{Conclusion}

Our study shows a fruitful dialogue between acquisition and syntactic mapping. We used cartographic insights as a detailed tool to understand the stage-by-stage unfolding of acquisition. Cartographic representations further allowed us to derive new predictions about acquisition that we then examined empirically. Reciprocally, data from development offered new evidence bearing on the cartographic organization, allowing us to adjudicate between alternative analytical hypotheses, and also raised new questions to further explore in the future.

\section{Appendix A: A description of the corpora we used for the new analyses we performed in Section 4}

Our new empirical analyses reported in Section 4 were performed on two types of spontaneous speech data: a corpus of 56 children, and a longitudinal database.

\section{Spontaneous speech corpus of 56 children}

Our new analyses of the corpus of 56 children were done on the same corpus used in Friedmann \& Reznick (this volume). The corpus included spontaneous speech samples of 56 children aged 1;66;1 (different from the children participating in the repetition task). The main criterion for selection of samples was that they will be large enough, so that they allow not only for the appearance of the structures that the child has already acquired, but also so it will be reasonable to conclude that if a certain structure did not appear in the sample, the child probably has not acquired it yet. The children who were 2;5 and older had an average of 151 utterances per sample (SD = 37); Some of the youngest children, aged 1;6-2;3, produced fewer utterances. So only samples in which the children had enough opportunity to produce utterances were included: sample with 50 clauses or less were included in the analysis only if they resulted from interactions that involved at least 100 turns. The average number of turns in samples with 50 clauses or less was 148. For the sake of comparability of the samples, we also limited the size of the samples that had more utterances to the first 200 utterances. The total number of utterances in the 56 samples was 6400 . We analysed, for each sample, whether a list of structures appeared at least once in the sample. The examination of order of acquisition within the corpus relied on a corpus wide analysis of the appearance of structures: if structure A appeared either alone or with structure B, but structure B did not appear in samples without structure A, we concluded that structure A was acquired before structure B.

\section{Longitudinal corpus of nine children}

In the longitudinal data we could examine the order of acquisition of various structures for each child, by analysing the relative timeline of acquisition of the various structures between children. To examine the patterns of acquisition within a single child, we analysed the spontaneous speech of nine children who were recorded several times. In Section 4.4 we selected for the general analysis the two children for whom the database is the richest: Hagar and Leor. Hagar was recorded 114 times between the ages of 1;7-2;11, with an average of 219 utterances per sample. Leor was recorded 79 times between 1;9-3;0, with an average of 297 utterances per sample. The total number of utterances analysed for these children was 16,002 .

In the analysis of yes/no questions compared to Wh questions in the longitudinal corpora we analyzed the corpora of 9 children: Hagar and Leor (described above), Lior, Naama, Smadar (the other three children reported in Friedmann \& Reznick, this volume), and 4 additional children who had somewhat fewer samples, but still enough to time the acquisition of questions (Sivan, Ruthy, Hamutal, Asaf from Ravid 2004), with 9-20 samplings and 971-3005 utterances, added here courtesy of Julia Reznick. 


\section{Abbreviations}

P.ACC $=$ the accusative case marker/differential object marker et, a structural marker of definite direct objects, with characteristics similar to preposition-like differential object markers in other languages, $\mathrm{PL}=$ plural, $\mathrm{SG}=$ singular, $\mathrm{FUT}=$ future, $\mathrm{FEM}=$ feminine

\section{Acknowledgements}

We are grateful to Julia Reznick for her collaboration and contribution.

\section{Funding information}

This research was supported by The Human Frontiers Science Program (RGP0057/201, Friedmann), and by the Lieselotte Adler Laboratory for Research on Child Development (Tel Aviv University, Friedmann).

\section{Competing interests}

The authors have no competing interests to declare.

\section{Author affiliations}

\section{Naama Friedmann}

Tel Aviv University, Tel Aviv, Israel

Adriana Belletti (D) orcid.org/0000-0002-1117-0721

University of Siena, Siena, Italy

Luigi Rizzi (D) orcid.org/0000-0002-2543-2112

Collège de France, Paris, France

\section{References}

Aboh, Enoch Olade. 2004. The morphosyntax of complement-head sequences: Clause structure and word order patterns in Kwa. New York: Oxford University Press. DOI: https://doi.org/10.1093/acprof:o so/9780195159905.001.0001

Adragão, Maria do Mar \& João Costa. 2004. On the status of preverbal subjects in null subject languages: Evidence from acquisition. In Jacqueline van Kampen \& Sergio Baauw (eds.), Proceedings of GALA 2003. The Hague: Utrecht University, Lot Publications.

Antinucci, Francesco \& Ruth Miller. 1976. How children talk about what happened. Journal of Child Language 3. 167-189. DOI: https://doi.org/10.1017/S0305000900001434

Armon-Lotem, Sharon. 1997. The minimalist child: Parameters and functional heads in the acquisition of Hebrew. Ph.D. Dissertation, Tel-Aviv: Tel-Aviv University.

Armon-Lotem, Sharon. 2006. Subject use and the acquisition of verbal agreement in Hebrew. In Natalia Gagarina \& Insa Gulzow (eds.), Acquisition of verb grammar and verb arguments, 269-291. Kluwer Academic Publishers.

Armon-Lotem, Sharon. 2008a. The interaction between question formation and verbal morphology in the acquisition of Hebrew: A minimalist perspective. In by Sharon Armon-Lotem, Gabi Danon \& Susan Rothstein (eds.), Current Issues in Generative Hebrew Linguistics Edited, 223-244 [Linguistik Aktuell/ Linguistics Today 134]. Benjamins. DOI: https://doi.org/10.1075/la.134.09the

Armon-Lotem, Sharon. 2008b. What can we learn from children's errors before the age of two: The acquisition of possession and verb agreement. In Galia Hatav (ed.), Theoretical Hebrew linguistics, 309-337. Jerusalem: Magnes. (in Hebrew).

Armon-Lotem, Sharon \& Ruth A. Berman. 2003. The emergence of grammar: Early verbs and beyond. Journal of Child Language 30(4). 845-877. DOI: https://doi.org/10.1017/S0305000903005750

Babyonyshev, Maria, Jennifer Ganger, David Pesetsky \& Kenneth Wexler. 2001. The maturation of grammatical principles: Evidence from Russian unaccusatives. Linguistic Inquiry 32. 1-44. DOI: https://doi.org/10.1162/002438901554577

Belletti, Adriana. 1988. The case of unaccusatives. Linguistic Inquiry 19. 1-34. https://www.jstor.org/ stable/4178572.

Belletti, Adriana. 2004. Aspects of the low IP area. In Luigi Rizzi (ed.), The structure of CP and IP, 16-51. New York: Oxford University Press. 
Belletti, Adriana. 2017. On the acquisition of complex derivations with related considerations on poverty of the stimulus and frequency. In Elisa Di Domenico (ed.), Syntactic complexity from a language acquisition perspective, 28-48. Cambridge Scholars Publishing.

Belletti, Adriana. 2020. Ways of smuggling in syntactic derivations. In Adriana Belletti \& Chris Collins (eds.), Smuggling in syntax. New York: Oxford University Press. DOI: https://doi.org/10.1093/ oso/9780197509869.001.0001

Belletti, Adriana \& Claudia Contemori. 2010. Intervention and attraction: On the production of subject and object relatives by Italian (young) children and adults. In João Costa, Ana Castro, Maria Lobo \& Fernanda Pratas (eds.), Language acquisition and development: Proceedings of GALA 2009, 39-52. Cambridge: Cambridge Scholars Press.

Belletti, Adriana \& Maria-Teresa Guasti. 2015. The acquisition of Italian. Morphosyntax and its interfaces in different modes of acquisition. John Benjamins, Language Acquisition and Language Disorders series. DOI: https://doi.org/10.1075/lald.57

Belletti, Adriana \& Valentina Bianchi. 2016. Definiteness effect and unaccusative subjects: An overview and some new thoughts. In Susann Fischer, Tanja Kupisch \& Esther Rinke (eds.), Definiteness effects: Bilingual, typological and diachronic variation, 14-65. Cambridge Scholars Publishing.

Belletti, Adriana, Naama Friedmann, Dominique Brunato \& Luigi Rizzi. 2012. Does gender make a difference? Comparing the effect of gender on children's comprehension of relative clauses in Hebrew and Italian. Lingua 122(10). 1053-1069. DOI: https://doi.org/10.1016/j.lingua.2012.02.007

Benincà, Paola \& Cecilia Poletto. 2004. Topic, Focus and V2: Defining the CP sublayers. In L. Rizzi (ed.), The structure of CP and IP: The cartography of syntactic structures volume 2: The cartography of syntactic structures, 52-75. Oxford/New York: Oxford University Press.

Bentea, Anamaria. 2016. Intervention effects in language acquisition: The comprehension of A-bar dependencies in French and Romanian. Geneva: University of Geneva unpublished dissertation.

Bianchi, Valentina. 1999. Consequences of antisymmetry: Headed relative clauses. Berlin: Mouton de Gruyter. DOI: https://doi.org/10.1515/9783110803372

Bianchi, Valentina, Giuliano Bocci \& Silvio Cruschina. 2016. Focus fronting, unexpectedness, and evaluative implicatures. Semantics and Pragmatics 9(3). 1-54. DOI: https://doi.org/10.3765/sp.9.3

Biran, Michal \& Esther Ruigendijk. 2015. Do case and gender information assist sentence comprehension and repetition for German-and Hebrew-speaking children? Lingua 164. 215-238. DOI: https://doi. org/10.1016/j.lingua.2015.06.012

Biran, Michal \& Naama Friedmann. 2012. The representation of lexical-syntactic information: Evidence from syntactic and lexical retrieval impairments in aphasia. Cortex 48(9). 1103-1127. DOI: https:// doi.org/10.1016/j.cortex.2011.05.024

Bocci, Giuliano, Luigi Rizzi \& Mamoru Saito. 2018. On the incompatibility of wh and focus. Gengo Kenkyu 154. 29-51. DOI: https://doi.org/10.11435/gengo.154.0_29

Borer, Hagit. 1984. Restrictive relatives in Modern Hebrew. Natural Language and Linguistic Theory 2. 219-260. https://www.jstor.org/stable/4047488. DOI: https://doi.org/10.1007/BF00133282

Borer, Hagit \& Kenneth Wexler. 1987. The maturation of syntax. In Thomas Roeper \& Edwin Williams (eds.), Parameter-setting and language acquisition, 123-172. Dordrecht: Springer.

Bottari, Piero, Paola Cipriani \& Anna Maria Chilosi. 1993. Protosyntactic devices in the acquisition of Italian free morphology. Language Acquisition 3(4). 327-369. DOI: https://doi.org/10.1207/ s15327817la0304_1

Burzio, Luigi. 1986. Italian syntax: A Government-Binding approach. Dordrecht: Reidel. DOI: https://doi. org/10.1007/978-94-009-4522-7

Cardinaletti, Anna. 2004. Towards a cartography of subject positions. In Luigi Rizzi (ed.), The cartography of syntactic structures. Vol 2, The structure of CP and IP, 115-165. New York: Oxford University Press.

Cheng, Lisa L. S. 1997. On the typology of Wh questions. Taylor \& Francis.

Chomsky, Noam. 1965. Aspects of the theory of syntax. Cambridge, MA: The MIT Press. DOI: https://doi. org/10.21236/AD0616323

Chomsky, Noam. 1995. The minimalist program. Cambridge, MA: MIT Press.

Chomsky, Noam. 2000. Minimalist inquiries. In Roger Martin, David Michaels \& Juan Uriagereka (eds.), Step by step: Essays on minimalist syntax in honor of Howard Lasnik, 89-155. Cambridge, MA: MIT Press.

Chomsky, Noam. 2001. Derivation by phase. In Michael Kenstowicz (ed.) Ken Hale: A Life in Language, 1-50. Cambridge, MA: MIT Press.

Cinque, Guglielmo. 1999. Adverbs and functional heads: A cross-linguistic perspective. New York \& Oxford: Oxford University Press.

Cinque, Guglielmo. 2020. The Syntax of relative clauses: A unified analysis. Cambridge: Cambridge University Press. DOI: https://doi.org/10.1017/9781108856195

Clahsen, Harald. 1990/1991. Constraints on parameter setting: A grammatical analysis of some acquisition stages in German child language. Language Acquisition 1. 361-391. https://www.jstor.org/ stable/20011360. DOI: https://doi.org/10.1207/s15327817la0104_3 
Clahsen, Harlad, Monika Eisenbeiss \& Martina Penke. 1996. Lexical learning in early syntactic development. In Harald Clahsen (ed.), Generative perspectives on language acquisition (Language Acquisition and Language Disorders 14), 129-161. Amsterdam: John Benjamins. DOI: https://doi. org/10.1075/lald.14.08cla

Clahsen, Harald, Martina Penke \& Teresa Parodi. 1993/1994. Functional categories in early child German. Language Acquisition 3. 395-429. DOI: https://doi.org/10.1207/s15327817la0304_3

Correa, Leticia M. 1982. Strategies in the acquisition of relative clauses. In Jean Aitchison \& Nigel Harvey (eds.), Working Papers of the London Psycholinguistic Research Group 4. 37-49.

Correa, Letícia M. Sicuro. 1995. An alternative assessment of children's comprehension of relative clauses. Journal of Psycholinguistic Research 24. 183-203. DOI: https://doi.org/10.1007/BF02145355

Costa, João \& Naama Friedmann. 2009. Hebrew and Arabic children going Romance: On the acquisition of word order in Semitic and Romance. In Enoch Olade Aboh, Elisabeth van der Linden, Josep Quer \& Petra Sleeman (eds.), Romance languages and linguistic theory 2007. (Current Issues in Linguistic Theory series), 51-66. Amsterdam: John Benjamins. DOI: https://doi.org/10.1075/rllt.1.03cos

Costa, João \& Naama Friedmann. 2012. Children acquire unaccusatives and A-movement very early. In Martin Everaert, Marijana Marelj \& Tal Siloni (eds.), The theta system: Argument structure at the interface. (Oxford Studies in Theoretical Linguistics 37). Oxford, UK: Oxford University Press. DOI: https://doi.org/10.1093/acprof:oso/9780199602513.003.0013

Costa, João, Naama Friedmann, Carolina Silva \& Maya Yachini. 2014. The boy that the chef cooked: Acquisition of PP relatives in European Portuguese and Hebrew. Lingua 150. 386-409. DOI: https:// doi.org/10.1016/j.lingua.2014.08.005

de Villiers Jill G. 1991. Why questions? In Thomas Maxfield \& Bernadette Plunkett (eds.), UMOP Special edition: Papers in the Acquisition of Wh, 155-175. Amherst, MA: GLSA

de Villiers Jill G., Peter A. de Villiers \& Esme Hoban. 1994. The central problem of functional categories in the English syntax of oral deaf children. In Helen Tager-Flusberg (ed.), Constraints on language acquisition: Studies of atypical children, 9-47. Hillsdale, NJ: Erlbaum.

De Vincenzi, Marica. 1991. Syntactic parsing strategies in Italian: The minimal chain principle. Dordrecht: Kluwer Academic Publishers. DOI: https://doi.org/10.1007/978-94-011-3184-1

Doron, Edit \& Lavi Wolf. 2016. Why rhetorical questions. In IATL 32. 25-26.

Emonds, Joseph. 1976. A transformational approach to English syntax. Academic Press.

Eyal, Sara. 1976. The acquisition of interrogative utterances in Hebrew-speaking children: Imitation comprehension and production. (Unpublished MA thesis) Tel Aviv University.

Friedmann, Naama. 2001. Agrammatism and the psychological reality of the syntactic tree. Journal of Psycholinguistic Research 30. 71-90. DOI: https://doi.org/10.1023/A:1005256224207

Friedmann, Naama. 2002a. The fragile nature of the left periphery: CP deficits in agrammatic aphasia. In Yehuda N. Falk (ed.), Proceedings of the $18^{\text {th }}$ IATL conference, 1-27. The Israeli Association for Theoretical Linguistics, The Hebrew University of Jerusalem.

Friedmann, Naama. 2002b. Question production in agrammatism: The Tree Pruning Hypothesis. Brain and Language 80. 160-187. DOI: https://doi.org/10.1006/brln.2001.2587

Friedmann, Naama. 2006. Speech production in Broca's agrammatic aphasia: Syntactic tree pruning. In Yosef Grodzinsky and Katrin Amunts (eds.), Broca's region. New York: Oxford University Press. DOI: https://doi.org/10.1093/acprof:oso/9780195177640.003.0005

Friedmann, Naama. 2007. Young children and A-chains: The acquisition of Hebrew unaccusatives. Language Acquisition 14(4). 377-422. DOI: https://doi.org/10.1080/10489220701600523

Friedmann, Naama, Adriana Belletti \& Luigi Rizzi. 2009. Relativized relatives: Types of intervention in the acquisition of A-bar dependencies. Lingua 119. 67-88. DOI: https://doi.org/10.1016/j. lingua.2008.09.002

Friedmann, Naama \& João Costa. 2010. The child heard a coordinated sentence and wondered: On children's difficulty in understanding coordination and relative clauses with crossing dependencies. Lingua 120(6). 1502-1515. DOI: https://doi.org/10.1016/j.lingua.2009.10.006

Friedmann, Naama \& João Costa. 2011. Acquisition of SV and VS order in Hebrew, European Portuguese, Palestinian Arabic, and Spanish. Language Acquisition 18(1). 1-38. DOI: https://doi.org/10.1080/1048 9223.2011.530507

Friedmann, Naama \& Hedva Lavi. 2006. On the order of acquisition of A-movement, Wh-movement and V-C movement. In Adriana Belletti, Elisa Bennati, Cristiano Chesi, Elisa Di Domenico \& Ida (eds.), Language acquisition and development, 211-217. Newcastle, UK: Cambridge Scholars Press.

Friedmann, Naama \& Julia Reznick. This volume. On the order of acquisition of various types of syntactic movement and embedding in Hebrew: Data from sentence repetition and from 27,696 utterances in spontaneous speech. Glossa.

Friedmann, Naama \& Rama Novogrodsky. 2004. The acquisition of relative clause comprehension in Hebrew: A study of SLI and normal development. Journal of Child Language 31. 661-681. DOI:

https://doi.org/10.1017/S0305000904006269 
Friedmann, Naama \& Yosef Grodzinsky. 1997. Tense and agreement in agrammatic production: Pruning the syntactic tree. Brain and Language 56. 397-425. DOI: https://doi.org/10.1006/brln.1997.1795

Friedmann, Naama \& Yosef Grodzinsky. 2000. Split inflection in neurolinguistics. In Marc-Ariel Friedemann \& Luigi Rizzi (eds.), The acquisition of syntax: Studies in comparative developmental linguistics, 84-104. Geneva, Switzerland: Longman Linguistics Library Series. DOI: https://doi. org/10.4324/9781315839899-4

Guasti, Maria Teresa. 1993/4. Verb syntax in Italian child grammar: Finite and non-finite verbs. Language Acquisition 3. 1-40. DOI: https://doi.org/10.1207/s15327817la0301_1

Guasti, Maria Teresa \& Luigi Rizzi 2002. Agreement and tense as distinctive syntactic positions. Evidence from acquisition. In Guglielmo Cinque (ed.), The Cartography of syntactic structures, 167-194. New York: Oxford University Press.

Guilfoyle, Eithne \& Máire Noonan. 1992. Functional categories and language acquisition. Canadian Journal of Linguistics 37(2). 241-272. DOI: https://doi.org/10.1017/S0008413100021976

Guttman, Louis. 1944. A basis for scaling qualitative data. American Sociological Review 9. 139-150. DOI: https://doi.org/10.2307/2086306

Guttman, Louis. 1950. The basis for scalogram analysis. In Samuel A. Stouffer, Louis Guttman, Edward A. Suchman, Paul F. Lazarsfeld, Shirley A. Star \& John A. Clausen (eds.), Measurement and prediction (Studies in Social Psychology in World War II. Vol. 4), 60-90. Princeton University Press.

Güven, Selçuk \& Naama Friedmann. 2019, September. The comprehension and production of relative clauses and Wh questions in turkish-speaking children with hearing impairment and children with developmental language disorder. Brain, Language \& Learning Conference, Siena, Italy.

Hamann, Cornelia \& Laurice Tuller. 2014. Genuine vs. pseudo-relatives in French: The depth of embedding factor. Rivista di Grammatica Generativa 36. 146-181.

Kayne, Richard. 1976. French relative 'que'. In F. Hensey \& M. Luján (eds.), Current studies in Romance linguistics, 255-299. Washington, DC: Georgetown University Press.

Kayne, Richard. 1994. The antisymmetry of syntax. Cambridge, MA: The MIT Press.

Khalaily, Samir \& Edit Doron. 2016. Colloquial Modern Hebrew doubly-marked interrogatives and contact with Arabic and Neo-Aramaic dialects. In Edit Doron (ed.), Language contact and the development of Modern Hebrew, 112-127. Leiden: Brill. DOI: https://doi.org/10.1163/9789004310896_010

Lebeaux, David. 1988. Language acquisition and the form of the grammar. Amherst: University of Massachusetts dissertation.

Lorusso, Paolo, Claudia Caprin \& Maria Teresa Guasti. 2005. Overt subject distribution in early Italian children. In Alejna Brugos, Manuella R. Clark-Cotton \& Seungwan Ha (eds.), A Supplement to the proceedings of the $29^{\text {th }}$ annual Boston University conference on language development (BUCLD).

Machida, Nanako, Shigeru Miyagawa \& Kenneth Wexler. 2004. A-chain maturation re-examined: Why Japanese children perform better on full unaccusatives than on passives. In Aniko Csirmaz, Andrea Gualmini \& Andrew Nevins (eds.), MITWPL48 Plato's problem. Papers in Language Acquisition. Cambridge, MA: MIT press.

Martini, Karen, Adriana Belletti, Carla Contemori \& Luigi Rizzi. 2018. On the role of lexical restriction and intervention in production: A new angle on the subject-object relatives asymmetry. $G G @ G$ (Generative Grammar in Geneva) 11. 120-134.

McKee, Cecile, Dana McDaniel \& Jesse Snedeker. 1998. Relative children say. Journal of Psycholinguistic Research 27. 573-596. DOI: https://doi.org/10.1023/A:1024901029643

Penner, Zvi \& Natasha Mueller. 1992. On the early stages in the acquisition of finite subordinate clauses. The syntax of the so-called preconjunctional subordinate clauses in German, Swiss German and French. Geneva Generative Papers 1(2), 163-181.

Perlmutter, David M. 1978. Impersonal passives and the Unaccusative Hypothesis. Proceedings of the Fourth Annual Meeting of the Berkeley Linguistics Society, 38. 157-189. Berkeley: University of California, Berkeley Linguistics Society. DOI: https://doi.org/10.3765/bls.v4i0.2198

Perlmutter, David M. \& Paul M. Postal. 1984. The 1-advancement exclusiveness law. In David Perlmutter \& Carol Rosen (eds.), Studies in Relational Grammar 2, 81-126. Chicago: University of Chicago Press.

Pierce, Amy E. 1992. Language acquisition and syntactic theory: A comparative analysis of French and English child grammars. Dordrecht, The Netherlands: Kluwer. DOI: https://doi.org/10.1007/978-94-011-2574$1 \_1$

Platzack, Christer. 1990. A grammar without functional categories: A syntactic study of early Swedish child language. Working Papers in Scandinavian Syntax 45. 13-34. DOI: https://doi.org/10.1017/ S0332586500002183

Prévost, Philippe \& Lydia White. 2000a. Accounting for morphological variation in second language acquisition: Truncation or missing inflection? In Mark-Ariel Friedemann, and Luigi Rizzi (eds.), The acquisition of syntax, 202-235. Longman. DOI: https://doi.org/10.4324/9781315839899-8

Prévost, Philippe \& Lydia White. 2000b. Missing surface inflection or impairment in second language acquisition? Evidence from tense and agreement. Second Language Research 16(2). 103-133. DOI: https://doi.org/10.1191/026765800677556046 
Puskás, Genoveva. 2000. Word order in Hungarian: The syntax of Ā-positions. Amsterdam: John Benjamins. DOI: https://doi.org/10.1075/la.33

Radford, Andrew. 1990. Syntactic theory and the acquisition of English syntax: The nature of early child grammars of English. Blackwell: Oxford.

Radford, Andrew. 1992. The acquisition of the morphosyntax of finite verbs in English. In Jürgen M Meisel (ed.), The acquisition of verb placement, 23-62. Dordrecht: Springer. DOI: https://doi. org/10.1007/978-94-011-2803-2_2

Radford, Andrew. 1996. Towards a structure-building model of acquisition. In Harald Clahsen (ed.), Generative perspectives on language acquisition: Empirical findings, theoretical considerations and crosslinguistic comparisons, 43-90. [Language Acquisition and Language Disorders 14]. DOI: https:// doi.org/10.1075/lald.14.06rad

Ramchand, Gillian. 2008. Aspect and predication: The semantics of argument structure. New York: Oxford University Press.

Ravid, Dorit. 2004. Dataset published via TalkBank. DOI: https://doi.org/10.21415/T5J88T

Rizzi, Luigi. 1990. Relativized Minimality. Cambridge MA: The MIT Press.

Rizzi, Luigi. 1993/4. Some remarks on linguistic theory and language development. Language Acquisition 3(4). 371-393. DOI: https://doi.org/10.1207/s15327817la0304_2

Rizzi, Luigi. 1997. The fine structure of the left periphery. In Liliane Haegeman (ed.), Elements of grammar, 281-337. Dordrecht: Kluwer. DOI: https://doi.org/10.1007/978-94-011-5420-8_7

Rizzi, Luigi. 2001. On the position INT(ERROGATIVE) in the left periphery of the clause. In Guglielmo Cinque \& Giampaolo Salvi (eds.), Current studies in Italian syntax, 287-296. Amsterdam: Elsevier. DOI: https://doi.org/10.1163/9780585473949_016

Rizzi, Luigi. 2004. Locality and left periphery. 2004. In Adriana Belletti (ed.), Structures and beyond - the cartography of syntactic structures 3. 223-251. Oxford-New York: Oxford University Press.

Rizzi, Luigi. 2006. Grammatically-based target-inconsistencies in child language. In Kamil Ud Deen, Jun Nomura, Barbara Schulz \& Bonnie D. Schwartz (eds.), The Proceedings of the Inaugural Conference on Generative Approaches to Language Acquisition-North America, Honolulu, HI. (Occasional Papers in Linguistics 4), 19-49. University of Connecticut.

Rizzi, Luigi. 2009. Movement and concepts of locality. In Massimo Piattelli-Palmarini, Juan Uriagereka and Pello Salaburu (eds.), Of minds and language: The Basque Country encounter with Noam Chomsky, 155-168. Oxford University Press.

Rizzi, Luigi. 2013a. Notes on cartography and further explanation. Probus 25(1). 197-226. DOI: https:// doi.org/10.1515/probus-2013-0010

Rizzi, Luigi. 2013b. A note on locality and selection. In Yoichi Miyamoto, Daiko Takahashi, and Hideki Maki (eds.), Deep insights, broad perspectives: Essays in honor of Mamoru Saito, 325-341. Tokyo: Kaitakusha.

Rizzi, Luigi \& Giuliano Bocci. 2017. Left periphery of the clause: Primarily illustrated for Italian. In Martin Everaert \& Henk C. van Riemsdijk (eds.), The Wiley Blackwell companion to syntax, 1-30. DOI: https://doi.org/10.1002/9781118358733.wbsyncom104

Rizzi, Luigi \& Guglielmo Cinque. 2016. Functional categories and syntactic theory. Annual Review of Linguistics 2. 139-163. DOI: https://doi.org/10.1146/annurev-linguistics-011415-040827

Rizzi, Luigi \& Ur Shlonsky. 2007. Strategies of subject extraction. In Hans-Martin Gärtner \& Uli Sauerland (eds.), Interfaces + Recursion = Language? Chomsky's Minimalism and the view from syntax-semantics, 115-160. Berlin, Germany: Mouton de Gruyter.

Ross, John Robert. 1973. The Penthouse Principle and the order of constituents. In Claudia W. Corum, Thomas Cedric Smith-Stark \& Ann Weiser (eds.), You take the high node and I'll take the low, 397-422.

Ruigendijk, Esther \& Naama Friedmann. 2017. A deficit in movement-derived sentences in Germanspeaking Hearing-Impaired children. Frontiers in Psychology 8(6891). 1-22. DOI: https://doi. org/10.3389/fpsyg.2017.00689

Saito, Mamoru. 2012. Sentence types and the Japanese right periphery. In Günther Grewendorf \& Thomas Ede Zimmermann (eds.), Discourse and grammar, studies in generative grammar, 147-175. BostonBerlin: Mouton de Gruyter. DOI: https://doi.org/10.1515/9781614511601.147

Salustri, Manola, Julia Berger-Morales \& Mariame Sy. 2004. Participial constructions in child grammar: Correlations with verb movement properties. LOT Occasional Series 3. 409-420.

Samo, Giuseppe. 2019. A criterial approach to the cartography of V2. Amsterdam/New York: Benjamins. DOI: https://doi.org/10.1075/la.257

Sano, Tetsuya, Mika Endo \& Kyoko Yamakoshi. 2001. Developmental issues in the acquisition of Japanese unaccusatives and passives. In Anna H.-J. Do, Laura Domínguez \& Aimee Johansen (eds.), BUCLD Proceedings 25. 668-683. Sommerville, MA: Cascadilla Press.

Shimada, Hiroyuki \& Tetsuya Sano. 2007. A-chains and unaccusative-unergative distinction in the child grammar: The acquisition of Japanese te-iru constructions. In Alyona Belikova, Luisa Meroni \& Mari Umeda (eds.), Proceedings of the 2nd Conference on Generative Approaches to Language Acquisition North America (GALANA), 386-393. Somerville, MA: Cascadilla Proceedings Project. 
Shlonsky, Ur. 1997. Clause structure and word order in Hebrew and Arabic. New York: Oxford University Press.

Shlonsky, Ur. 2014. Topicalization and focalization: A preliminary exploration of the Hebrew left periphery. In Anna Cardinaletti, Guglielmo Cinque \& Yoshio Endo (eds.), Peripheries: Clause-initial and clause-final positions, 327-341. Tokyo: Hitsuzi Synobo.

Shlonsky, Ur \& Gabriela Soare. 2011. “Where's why?” Linguistic Inquiry 42. 651-669. DOI: https://doi. org/10.1162/LING_a_00064

Snyder, William, Nina Hyams \& Paola Crisma. 1995. Romance auxiliary selection with reflexive clitics: Evidence for early knowledge of unaccusativity. In Proceedings of the 26th Annual Child Language Research Forum, 127-136.

Soare, Gabriela (ed.). 2021. Why is 'Why' unique: Its syntactic and semantic properties. Amsterdam/New York: John Benjamins Publishing. DOI: https://doi.org/10.1515/9783110675160

Starke, Michal. 2001. Move dissolves into merge: A theory of locality. Geneva: Université de Genève dissertation.

Stavrakaki, Spiridoula. 2001. Comprehension of reversible relative clauses in specifically language impaired and normally developing Greek children. Brain and Language 77(3). 419-431. DOI: https:// doi.org/10.1006/brln.2000.2412

Stromswold, Karin. 1995. The acquisition of subject and object Wh question. Language Acquisition 4. 5-48. DOI: https://doi.org/10.1207/s15327817la0401\&2_1

Thornton, Rosalind. 2008. Why continuity. Natural Language and Linguistic Theory 26. 107-146. DOI: https://doi.org/10.1007/s11049-007-9031-\%

Thornton, Rosalind. 2016. Acquisition of questions. In Jeffrey L. Lidz, William Snyder \& Joe Pater (eds.), The Oxford handbook of developmental linguistics. Oxford: Oxford University Press. DOI: https://doi. org/10.1093/oxfordhb/9780199601264.013.14

Tsimpli, Ianthi M. 2005. Peripheral positions in early Greek. In Melita Stavrou \& Arhonto Terzi (eds.), Advances in Greek generative syntax (Linguistics Today), 179-216. Amsterdam: John Benjamins. DOI: https://doi.org/10.1075/la.76.08tsi

Wexler, Kenneth. 2004. Theory of phasal development: Perfection in child grammar. MIT Working Papers in Linguistics 48. 159-209.

Zanuttini, Raffaella. 2017. Presentatives and the syntactic encoding of contextual information. In Enoch Aboh, Eric Haeberli, Genoveva Puskás \& Manuela Schönenberger (eds.), Elements of comparative syntax: Theory and description, 221-255. Boston/Berlin: De Gruyter. DOI: https://doi. org/10.1515/9781501504037-008

Zanuttini, Raffaella \& Paul Portner. 2003. Exclamative clauses: At the syntax-semantics interface. Language 79(1). 39-81. DOI: https://doi.org/10.1353/lan.2003.0105

Zuckerman, Shalom. 2001. The acquisition of "optional" movement. Groningen dissertations in linguistics 34. Rijksuniversiteit Groningen.
Friedmann et al. Glossa: a journal of general linguistics DOI: $10.16995 /$ glossa.5877
TO CITE THIS ARTICLE: Friedmann, Naama, Adriana Belletti and Luigi Rizzi. 2021. Growing trees: The acquisition of the left periphery. Glossa: a journal of general linguistics 6(1): 131 1-38. DOI: https://doi. org/10.16995/glossa.5877

Submitted: 10 April 2020 Accepted: 29 March 2021 Published: 22 October 2021

\section{COPYRIGHT:}

(c) 2021 The Author(s). This is an open-access article distributed under the terms of the Creative Commons Attribution 4.0 International License (CC-BY 4.0), which permits unrestricted use, distribution, and reproduction in any medium, provided the original author and source are credited. See http:// creativecommons.org/ licenses/by/4.0/.

Glossa: a journal of general linguistics is a peer-reviewed open access journal published by Open Library of Humanities. 